\title{
The construction of the Crystal Houses façade: challenges and innovations
}

\author{
F. Oikonomopoulou - T. Bristogianni • \\ F. A. Veer - R. Nijsse
}

Received: 28 September 2016 / Accepted: 9 March 2017 / Published online: 11 April 2017

(C) The Author(s) 2017. This article is an open access publication

\begin{abstract}
A novel glass brick façade has been designed and engineered to reproduce the original brick façade of a former townhouse in Amsterdam. Based on the original design the resulting façade comprises more than 6500 solid glass bricks, reinterpreting the traditional brick pattern, and elaborated cast glass elements for the replication of the window and door frames. To achieve unhindered transparency, the 10 by $12 \mathrm{~m}$ glass block façade has to be self-supporting. Previous experimental work by Oikonomopoulou et al. (J Facade Design Eng 2(3-4):201-222, 2015b. doi:10. $3233 /$ fde-150021) concluded that it was necessary to use a clear, UV-curing adhesive of high stiffness as bonding material. Experimental work on prototype elements indicated that the desired monolithic structural performance of the glass masonry system, as well as a homogeneous visual result, are only achieved when the selected adhesive is applied in a $0.2-0.3 \mathrm{~mm}$ thick layer. The nearly zero thickness of the adhesive together with the request for unimpeded transparency introduced numerous engineering challenges. These include
\end{abstract}

F. Oikonomopoulou ( $\varangle) \cdot$ F. A. Veer $\cdot$ R. Nijsse Department of Architectural Engineering and Technology, Faculty of Architecture and the Built Environment, Delft University of Technology, Delft 2628 BL, The Netherlands e-mail: f.oikonomopoulou@tudelft.nl

T. Bristogianni $\cdot$ R. Nijsse

Department of Structural Engineering, Faculty of Civil Engineering and Geosciences, Delft University of Technology, Delft 2628 CN, The Netherlands the production of highly accurate glass bricks and the homogeneous application of the adhesive to achieve the construction of the entire façade with remarkably tight allowable tolerances. This paper presents the main challenges confronted during the construction of the novel façade and records the innovative solutions implemented, from the casting of the glass units to the completion of the façade. Based on the conclusions of the research and the technical experience gained by the realization of the project, recommendations are made on the further improvement of the presented glass masonry system towards future applications.

Keywords Structural glass - Solid glass bricks · Adhesive glass connections · Glass masonry · Crystal Houses façade $\cdot$ Cast glass

\section{Introduction}

A novel glass masonry façade has been designed and engineered to replace the brick façade of a former townhouse in Amsterdam, aiming to preserve the city's traditional architectural style and historical ensemble. Designed by the MVRDV architectural studio (www. mvrdv.nl), the innovative façade follows the original nineteenth century elevation down to the layering of the bricks and the details of the window frames, but is stretched vertically to comply with updated zoning laws and allow for increased interior space (MVRDV Architects 2016). Based on the brick modules of the 


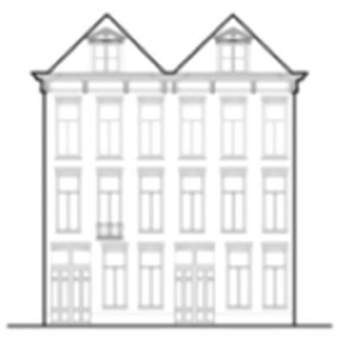

ORIGINAL FACADE

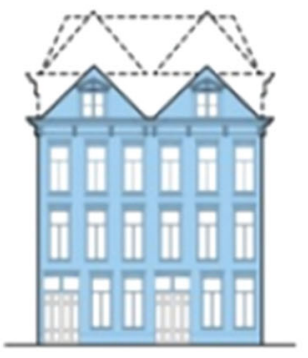

OLD PLEITER FACADE REBUILT IN GLASS

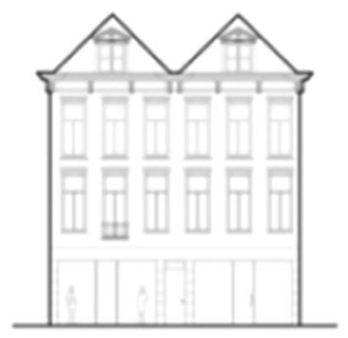

EXISTING SITUATION

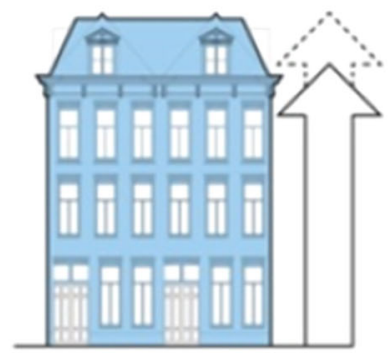

FACADE STRETCHED TO FIT NEW VOLUME

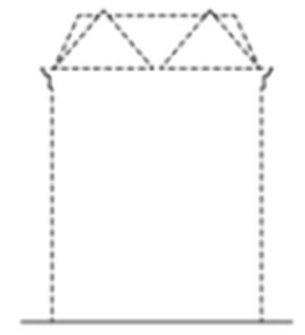

HOUSES REPLACED WITH LARGER VOLUMES

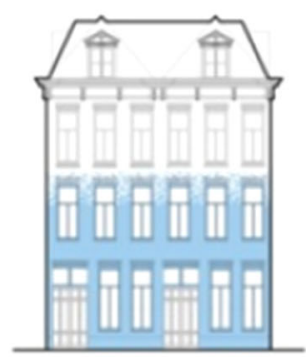

GLASS TO TERRACOTTA BRICK GRADIENT

Fig. 1 Illustration by MVRDV of the concept behind the Crystal Houses façade

original masonry façade, the 10 by $12 \mathrm{~m}$ transparent elevation employs more than 6500 solid glass bricks, each $210( \pm 1) \mathrm{mm}$ thick by $65( \pm 0.25) \mathrm{mm}$ high, reinterpreting the traditional brickwork and the characteristic architraves above the openings; while massive cast glass elements reproduce the classic timber door and window frames. As it ascends, terracotta bricks intermingle with glass ones, gradually transforming the glass elevation to the traditional brick façade of the upper floor (see Figs. 1, 2). The architects' desire for unimpeded transparency excluded the use of a metal substructure, rendering the choice for an entirely selfsupporting glass brick system as a necessary and so far unique solution.

\section{Principles of the adhesively bonded, solid glass block wall}

An illustration of the structural scheme followed for maximizing transparency is shown in Fig. 3. Based on previous realized examples of solid glass block façades
Oikonomopoulou et al. (2015b), lists three intertwined factors that define the structural performance and the transparency level of a self-supporting glass block façade: (1) the choice between hollow or solid glass bricks, (2) the choice between structural adhesive bonding or supporting substructure and (3) the façade's overall geometry. In principle, a bearing wall of the aforementioned size employing exclusively solid glass bricks is feasible owing to the compressive strength of glass (stated between 400-600 MPa for uniaxial loading by Fink (2000) and 300-420 MPa by Granta Design Limited (2015) and the considerable cross-section of the solid glass bricks $(210 \mathrm{~mm})$ that allow the façade to carry its dead load and have an enhanced buckling resistance. In comparison, a wall of the same dimensions comprising hollow glass blocks would require a supporting sub-structure. Their reduced thickness results in internal buckling or stress concentrations that in turn lead to a relatively low stated resistance in compressive load [defined as low as $6 \mathrm{MPa}$ in ISO 21690:2006 by International Organization for Standardization (2006)]. The lateral stability of the façade is guaranteed by 
Fig. 2 Left 3-D visualization of the façade by MVRDV. Right The realized façade
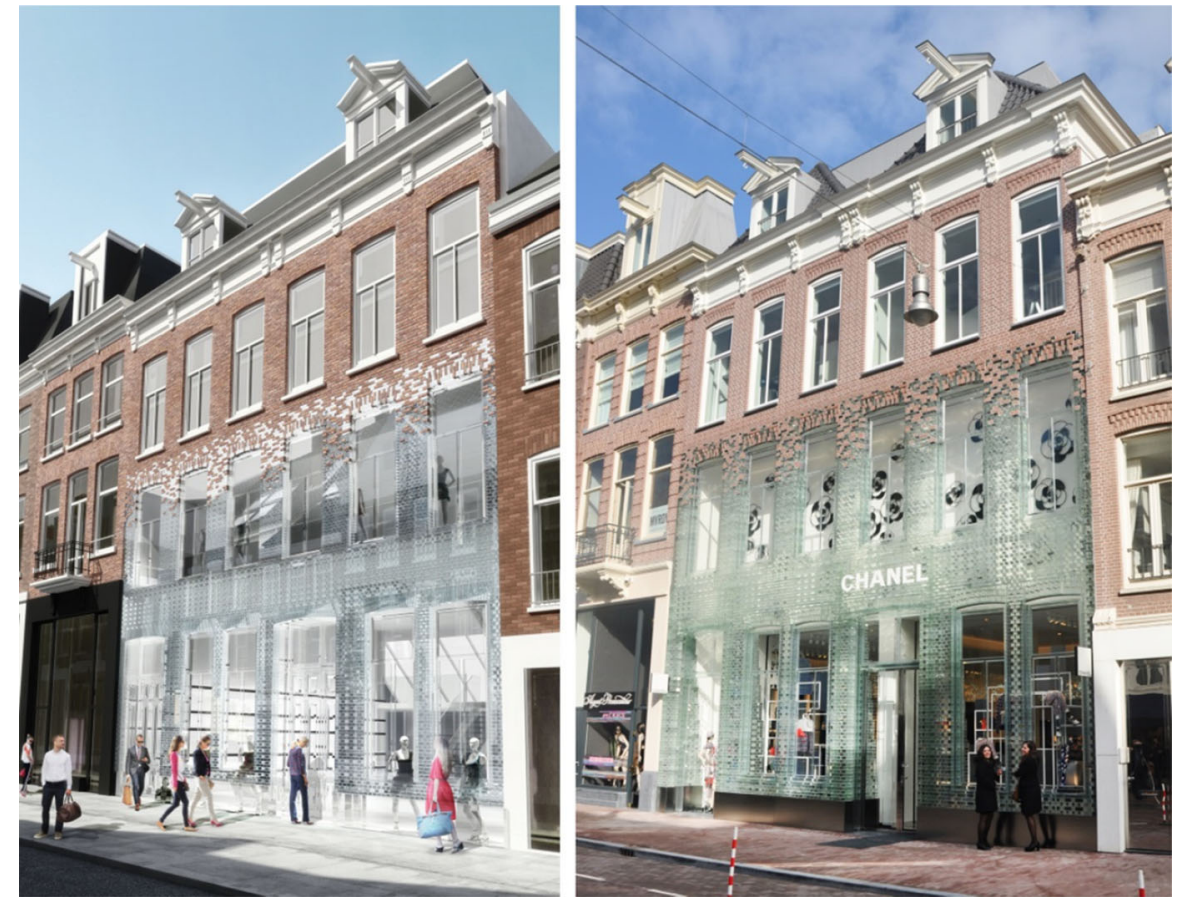

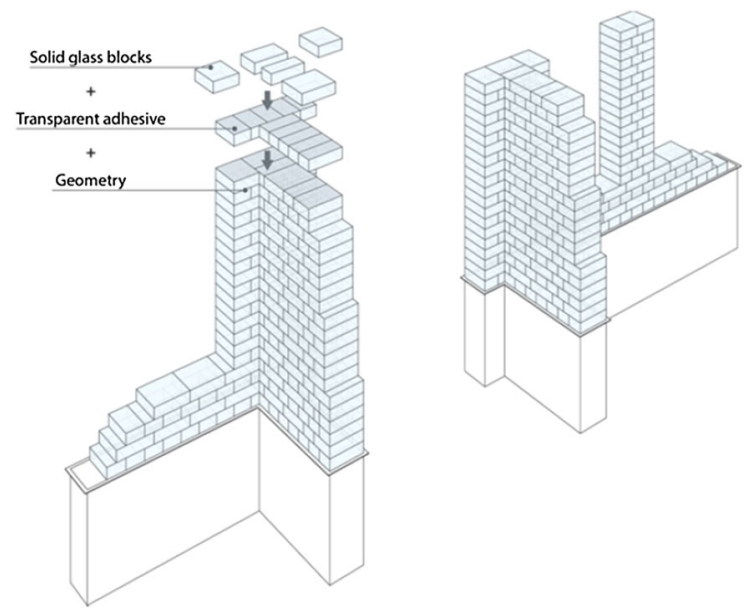

Fig. 3 Principle of the proposed structural glass system

four buttresses erected towards the interior by interlaced glass bricks, resulting in a continuous envelope of increased rigidity.

An entirely transparent structural system is obtained by bonding the glass bricks together with a clear adhesive. In the developed system, the mechanical properties of this adhesive are equally critical to the ones of the glass blocks; it is their interaction as one structural unit that defines the system's structural capacity and behaviour. The most favourable structural performance is when adhesive and glass bricks fully cooperate and the masonry wall behaves as a single rigid unit under loading, resulting in a homogeneous load distribution. Extended research and testing of various adhesive types by Oikonomopoulou et al. (2015b) lead to the eventual selection of Delo Photobond 4468; a colorless, UV-curing, one-component acrylate of the Delo Photobond family, designed for high strength bonding between glass components. Adhesives of the Delo Photobond family have already been applied for the bonding of all-glass structures, i.e. in the frames of the glass shell of the Leibniz Institute for Solid State and Materials Research (Delo Industrial Adhesives 2011).

The selected adhesive is optimized for high force transduction in glass/glass and glass/metal bonds and presents high shear stiffness, good short and long term compressive behavior and high humidity resistance (Delo Industrial Adhesives 2014). Visually, besides being colorless, it has a similar refractive index to glass (1.5) and does not discolor when exposed to sunlight. Another important feature is its photo-catalytic curing, allowing for fast construction: The adhesive can be fully cured in a minimum of $40 \mathrm{~s}$ using $60 \mathrm{~mW} / \mathrm{cm}^{2}$ UVA intensity (Delo Industrial Adhesives 2014). After curing, it obtains its full structural capacity and becomes moisture- and water- resistant. 


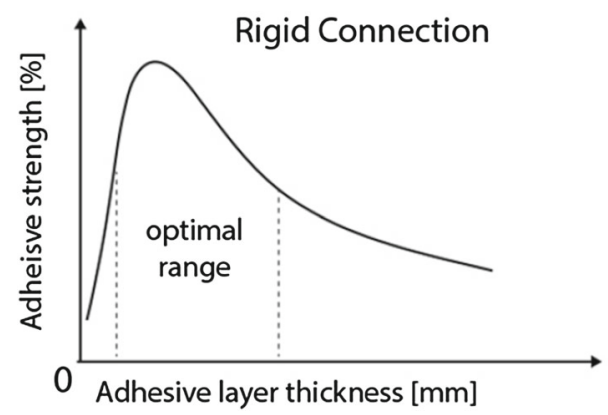

Fig. 4 Schematic illustration of the relation between a stiff adhesive's strength and thickness by Riewoldt (2014), den Ouden (2009), Wurm (2007)

The medium viscosity of the selected acrylate [7000 $\mathrm{mPas}$ at $23^{\circ} \mathrm{C}$, measured by Brookfield viscosimeter (Delo Industrial Adhesives 2014)] suggested that only the horizontal surfaces of the glass bricks are bonded; the vertical ones are left dry, allowing as well for thermal expansion.

There are no clear guidelines from the adhesive manufacturer on the recommended application thickness of Delo Photobond 4468. To the knowledge of the authors, there is not yet a generally approved theory concerning the effect of adhesive thickness in the strength of the bond. Although the classical elastic analyses predict that the strength increases with the adhesive thickness, experimental results show the opposite (da Silva et al. 2006). Research by Grant et al. (2009), da Silva et al. (2006), and Crocombe (1989) suggests different reasons ${ }^{1}$ why a thicker bondlayer provides a decreased joint strength. Based on experimental work by den Ouden (2009) and Riewoldt (2014), Fig. 4 exhibits how a comparatively thicker layer can negatively influence a rigid (i.e. epoxy or acrylate) adhesive's bond strength and subsequently the structural performance of the entire system. In practice Wurm (2007) mentions that acrylates present their highest strength in an application thickness between 0.1 and $0.5 \mathrm{~mm}$, whereas Puller and Sobek (2008) suggest an optimum thickness of $0.2 \mathrm{~mm}$ for a glass to metal bond with Delo Photobond 4468 .

\footnotetext{
${ }^{1}$ Crocombe (1989) suggests that thicker single-lap joints have a lower strength considering the plasticity of the adhesive, whereas da Silva et al. (2006) found that interface stresses are higher for thicker bondlines. Grant et al. (2009) suggests that as the bondline thickness of a $\mathrm{T}$ joint increases, there is an increase in the bending stress since the bending moment increases, reducing the strength of the joint.
}

In our case, structural and visual experiments indicated an optimum joint thickness for the selected adhesive between 0.2 and $0.3 \mathrm{~mm}$. Small wall prototypes by Oikonomopoulou et al. (2015b), comprising glass elements of different tolerance range, pointed out that a homogeneous bond thicker than $0.3 \mathrm{~mm}$ cannot be obtained due to the adhesive's flow properties and medium viscosity. Besides compromising the visual result, inconsistent bonding introduces weaker structural zones. Especially voids against the glass substrate in stiff adhesives can cause major stress concentrations (O' Regan 2014). Series of four-point bending tests in a Zwick Z100 displacement controlled universal testing machine, with a speed of $2 \mathrm{~mm} / \mathrm{min}$ and failure at a nominal flexural stress between 4.79 and 7.01 MPa demonstrated that the chosen adhesive enables the glass brick wall to behave monolithically under loading, when the adhesive is applied in a uniform layer of the optimum thickness (Oikonomopoulou et al. 2015a). The characteristic failure pattern can be seen in Fig. 5: Failure occurs with a straight cut, parallel to the loading path, splitting the specimen in two as if it was one solid component. Specifically, the glass block of the middle horizontal layer, spanning the vertical joint of the top and bottom layers, is split in half. No significant delamination is observed.

Based on the adhesive's optimum application thickness, it was determined that the glass blocks' top and bottom surfaces should be flat within $0.25 \mathrm{~mm}$ for guaranteeing an even adhesive layer of the highest strength.

The adhesive's medium viscosity and ideal thickness of a quarter of a millimeter together with the elastic nature of glass require exceptionally strict tolerances for a homogeneous application. The presented system is fundamentally different from a conventional mortar masonry, where the mortar can accommodate possible discrepancies in size and surface quality of the bricks. In this case, any accumulated deviation larger than the required $0.2-0.3 \mathrm{~mm}$ thickness of the adhesive could lead to uneven and improper bonding. Therefore, not only the size of each brick, but also the thickness of each construction layer have to be confined within a tight dimensional precision of a quarter of a millimeter. The demand of this unprecedented high level of accuracy and transparency, introduced various challenges in the engineering and construction of the Crystal Houses façade, calling for innovative solutions. Such challenges and their solutions are presented below. 

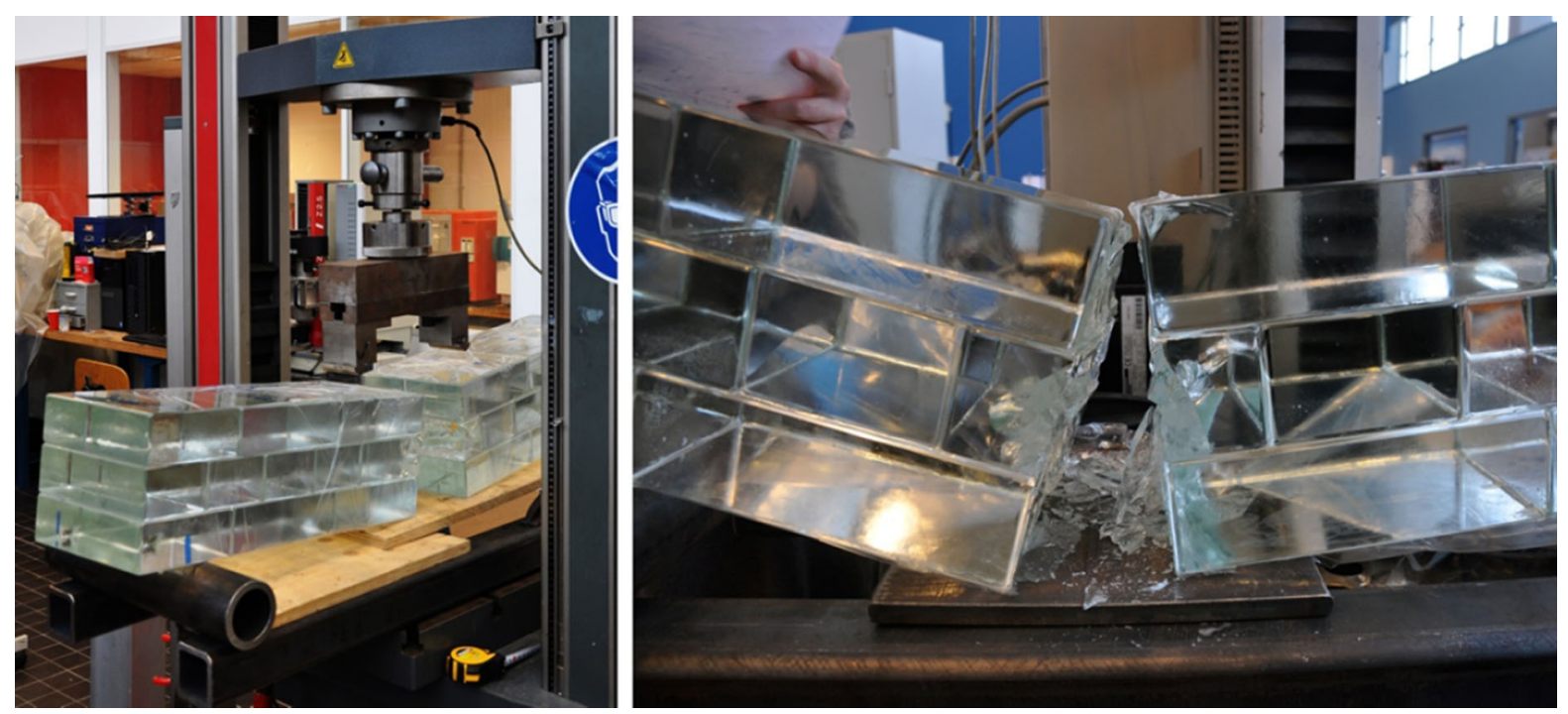

Fig. 5 Failure pattern of the glass beams

\section{Manufacturing and quality control of the glass blocks}

The required $\pm 0.25 \mathrm{~mm}$ tolerance influenced the choice of glass recipe and mould used. Solid glass bricks of comparable dimensions $(200 \mathrm{~mm} \times 300$ $\mathrm{mm} \times 70 \mathrm{~mm}$ ), used in the Atocha Memorial, the only other adhesively bonded glass block envelope, utilized borosilicate glass and precision press moulds for obtaining highly accurate units (Schober et al. 2007). Borosilicate glass was favoured over soda-lime glass owing to its comparably lower thermal expansion coefficient $\left[3.2-4 \times 10^{-6} / \mathrm{K}\right]$ over soda-lime glass [9.1$\left.9.5 \times 10^{-6} / \mathrm{K}\right]$ (Granta Design Limited 2015). This results in considerably less natural shrinkage during cooling and accordingly to a cast element of higher dimensional accuracy. A high precision press mould further confines the cast element to the desired dimensions, by pressing the molten glass during the initial, rapid cooling stage. The dimensional tolerance achieved with this method for the aforementioned glass bricks was $\pm 1.0 \mathrm{~mm}$ (Paech and Goppert 2008) without any machine processing. However, in the case of the Crystal Houses, the required $\pm 0.25 \mathrm{~mm}$ tolerance necessitates the mechanical post- processing of the blocks' horizontal (bonding) surfaces, even for borosilicate glass. Therefore, soda-lime glass and open precision moulds were opted for the final brick fabrication to avoid an unnecessary increase in manufacturing costs. Soda-lime is the least expensive form of glass (Corning Museum of Glass 2011) and requires a significantly lower working temperature than borosilicate [melting temperature is approximately $1200-1400^{\circ} \mathrm{C}$ compared to $1400-1600^{\circ} \mathrm{C}$ (Shand 1968)]. As a drawback, the higher thermal expansion coefficient of sodalime requires a considerably longer annealing time and thus manufacturing time of the components. For example, the borosilicate glass blocks of $70 \mathrm{~mm} \times 200 \mathrm{~mm}$ $\times 300 \mathrm{~mm}$ in dimensions and $8.4 \mathrm{~kg}$ weight (shown in Fig. 6), used in the Atocha Memorial, required a total annealing time of circa $20 \mathrm{~h}$ each (Paech and Goppert 2008). Whereas, the comparatively smaller soda-lime glass bricks of $65 \mathrm{~mm} \times 210 \mathrm{~mm} \times 210 \mathrm{~mm}$ in dimensions and $7.2 \mathrm{~kg}$ weight used in this project, required $36-38 \mathrm{~h}$ of annealing time respectively. High precision open moulds were preferred over press moulds, since the use of the latter was considered an expensive and unnecessary solution in view of the inevitable postprocessing.

To ensure that the higher expansion coefficient of soda-lime glass will not result in excessive thermal stresses on the façade, a simulation of the expected thermal loads in a yearly cycle was performed by an external company specializing in building physics. Based on the optical transmittance data provided by TU Delft for the solar gain (see Fig. 7), the orientation of the specific location, the height of the surrounding buildings and the assumption of a constant heating load in 

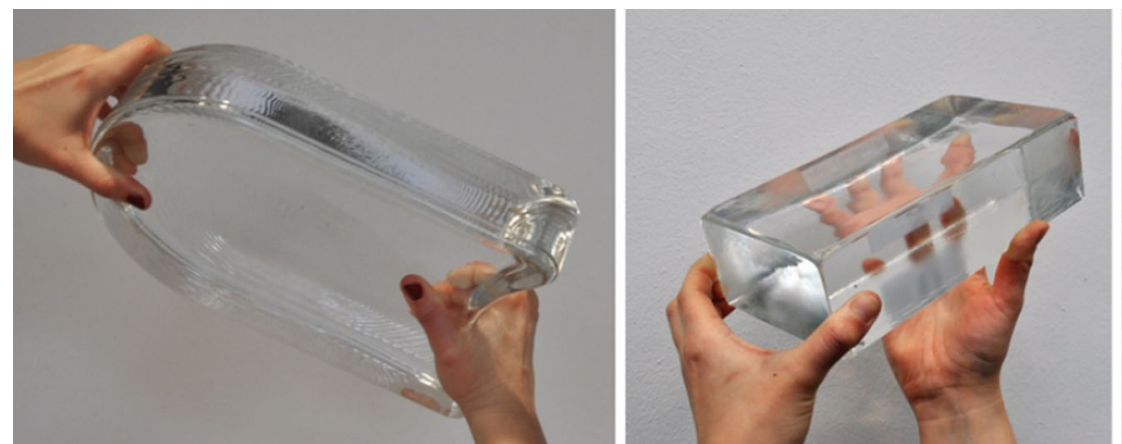

Fig. 6 Left: the $300 \times 200 \times 70 \mathrm{~mm}$ borosilicate glass block of the Atocha Memorial made by press mould. Center: a $210 \times 105$ $\times 65 \mathrm{~mm}$ soda-lime glass block of the Crystal Houses prior to

Fig. 7 Optical transmittance data of a standard Poesia brick by Tijssen (2014)

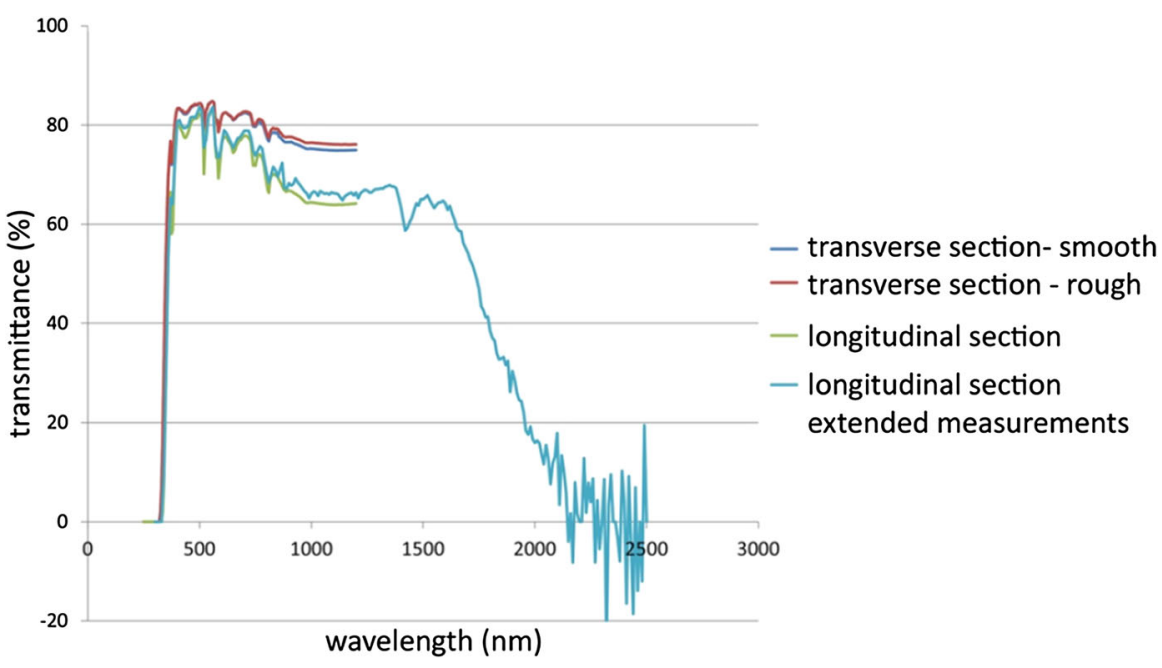

post-processing. Right: a $210 \times 105 \times 65 \mathrm{~mm}$ soda-lime glass block of the Crystal Houses after post-processing

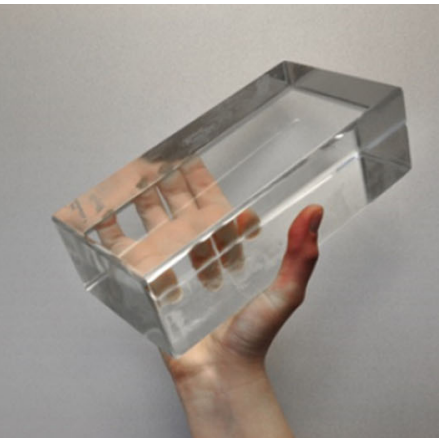

winter and cooling load in summer from the indoors airconditioning, heat and light transmittance of the wall were simulated. The results indicated acceptable thermal strains (less than $14.3 \times 10^{-3}$ ) for the soda-lime cast glass even under the most extreme weather conditions for Amsterdam.

The fabrication of the approximately 7500 solid glass bricks was assigned to the Italian company Poesia (http://www.spaziopoesia.it). Each brick is manually cast by pouring molten glass in high precision, open steel moulds with a removable bottom surface (see Fig. 8). A low-iron glass recipe is used for high optical quality. The final chemical composition of the glass, as measured by a X-ray fluorescence (XRF) spectrometer, is shown in Table 1. To attain the desired smooth external texture the steel moulds are preheated to a constant temperature of approximately $650-750^{\circ} \mathrm{C}$. If the mould's temperature falls below this range, then the hot glass coming into contact with the metal surface freezes instantly, creating a rough, wavy surface. On the other hand, if the mould is heated to a higher temperature, the glass tends to adhere to the walls of the mould. A release coating on the moulds further prevents the adhesion of the molten glass to the working surface and the development of micro-cracks.

After the glass is poured into the mould, it is left at ambient temperature to rapidly cool until $\sim 700^{\circ} \mathrm{C}$. This rapid cooling through the critical crystallization zone is essential to avoid the molecular arrangement of the melt in crystals instead of an amorphous structure, which would result in a cloudy glass of reduced transparency (Shelby 2005). During this initial cooling phase, the glass has still low viscosity that can allow any induced thermal stress to relax out to a negligible amount immediately (Shelby 2005). After the glass 

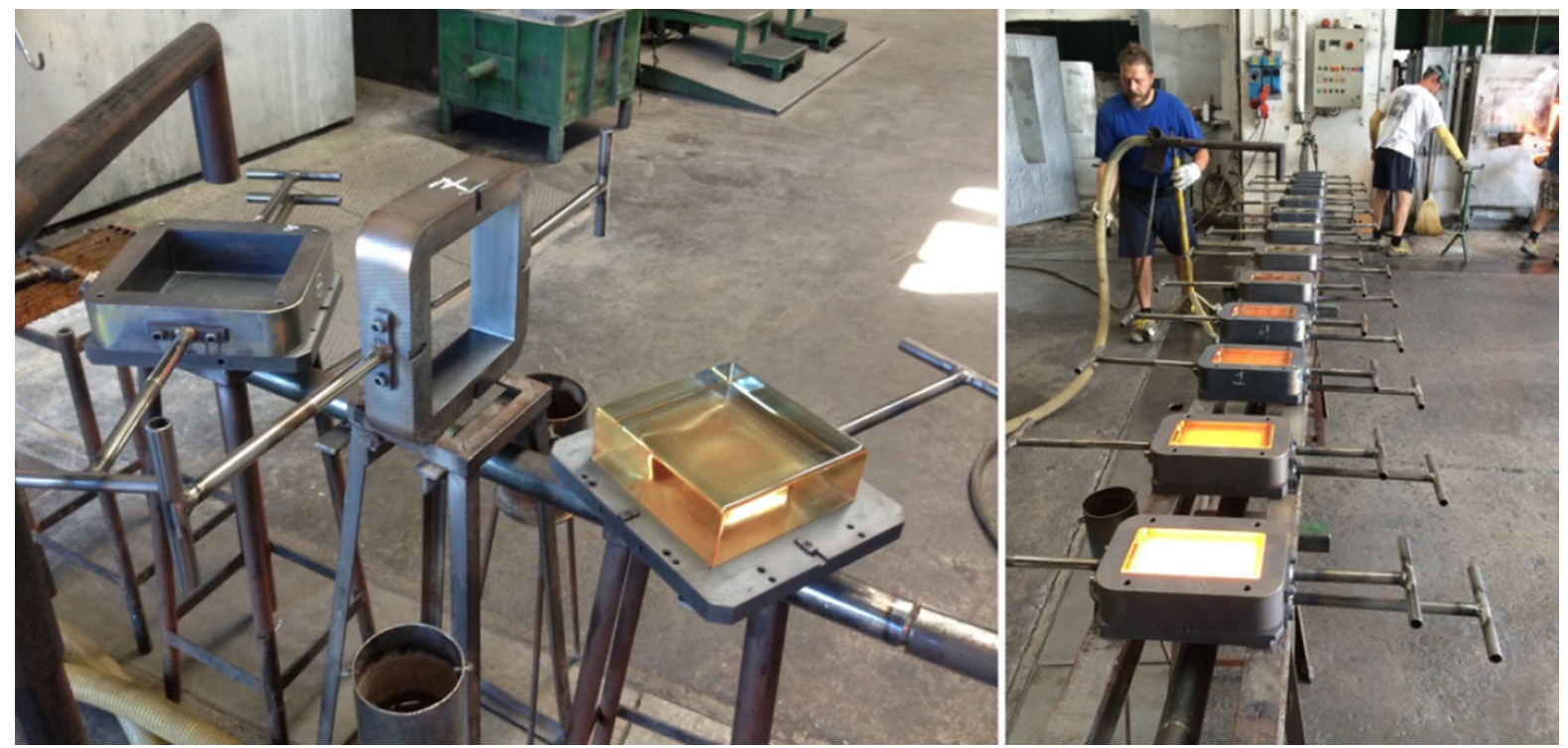

Fig. 8 Left: The high precision, open steel moulds. Right: Molten glass bricks during the rapid cooling phase from 1200 to $\sim 700{ }^{\circ} \mathrm{C}$ degrees

Table 1 Composition of the applied cast glass based on XRF chemical analysis

\begin{tabular}{lllllllll}
\hline Compound & $\mathrm{Wt} \%$ & $\begin{array}{l}\text { Absolute } \\
\text { error (wt\%) }\end{array}$ & Compound & $\mathrm{Wt} \%$ & $\begin{array}{l}\text { Absolute } \\
\text { error (wt\%) }\end{array}$ & Compound & $\begin{array}{c}\text { Wt\% } \\
\text { Absolute } \\
\text { error (wt\%) }\end{array}$ \\
\hline $\mathrm{SiO}_{2}$ & 75.606 & 0.1 & $\mathrm{Sb}_{2} \mathrm{O}_{3}$ & 0.821 & 0.03 & $\mathrm{ZrO}_{2}$ & 0.043 & 0.006 \\
$\mathrm{Na}_{2} \mathrm{O}$ & 15.833 & 0.1 & $\mathrm{CuO}$ & 0.402 & 0.02 & $\mathrm{SO}_{3}$ & 0.034 & 0.006 \\
$\mathrm{CaO}$ & 5.142 & 0.07 & $\mathrm{Al}_{2} \mathrm{O}_{3}$ & 0.165 & 0.01 & $\mathrm{TiO}_{2}$ & 0.02 & 0.004 \\
$\mathrm{~K}$ & 1.836 & 0.04 & $\mathrm{MgO}$ & 0.072 & 0.008 & $\mathrm{Fe}_{2} \mathrm{O}_{3}$ & 0.01 & 0.003 \\
\hline
\end{tabular}

temperature drops to its softening point $\left(\sim 720^{\circ} \mathrm{C}\right),^{2}$ the viscosity of the glass is sufficient for it to retain its shape and not deform under its own weight (Shand 1968). At $\sim 700^{\circ} \mathrm{C}$, the glass element is removed from the mould by suction at the top surface, and moved into the annealing oven.

There, a long and meticulously controlled annealing process eliminates any possible differential strain built up between casting and demoulding, as well as prevents the generation of internal residual stresses during further cooling. Upon this point, key reference temperatures are the annealing point $\left(\sim 545^{\circ} \mathrm{C}\right)$ and the

\footnotetext{
2 The temperatures given here for the softening, annealing and strain points are indicative for soda-lime glass and are based on research by Napolitano and Hawkins (1964). The values may differ according to the exact composition of the glass. The exact temperatures referring to the soda-lime recipe of the glass blocks have not been disclosed to the authors by Poesia.
}

strain point $\left(\sim 505^{\circ} \mathrm{C}\right)$ of soda-lime glass. The annealing point is defined as the temperature at which the viscosity of glass will allow any induced stress to relax out substantially in just a few minutes (Shelby 2005). The strain point is the temperature where the same stress is reduced to acceptable values in $4 \mathrm{~h}$ (Shand and Armistead 1958; Shand 1968). The cast glass should be maintained for adequate time at the annealing point to relieve any existing strains and then cooled at a rate sufficiently slow so that residual stresses will not reappear when the glass temperature has reached equilibrium (Shand and Armistead 1958). Effectively, below the strain point, stress cannot relax in time and is considered permanent (Watson 1999). When the temperature of the entire glass component has dropped below the strain point, the component can cool at a faster pace until ambient temperature, yet still sufficiently slow to prevent breakage due to thermal shock (Shand and Armistead 1958). 

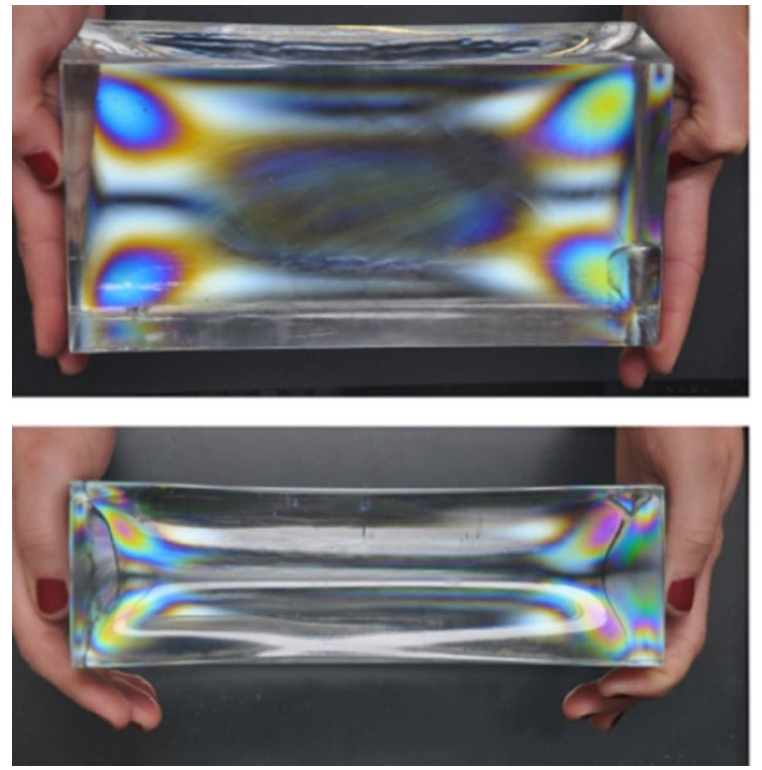

Fig. 9 Qualitative analysis of strain concentration by polarization test. Bricks such as the ones shown on the left image, with a clear indication of residual stresses, were discarded. Specimens

Accordingly, during the annealing range, the magnitude of the resulting internal stresses, is largely determined by the temperature difference between the warmest and coolest parts of the glass, its coefficient of expansion and the thickness of the section (Shand and Armistead 1958). However, the heat transfer needed for accomplishing the desired temperature difference in practice is influenced by various parameters that are challenging to accurately simulate. These include the element's shape and mass distribution, its sides exposed to cooling, the existence and amount of other thermal masses in the furnace, as well as the geometry and characteristics of the furnace itself. There are several guides on the annealing cycle of cast objects in the scientific and industrial literature, but they are often tailored to very specific circumstances and include unclear assumptions (Watson 1999).

Hence, even though the heat transfer needed for preventing considerable stresses in a cast glass element can be calculated, due to all the above reasons, in practice, the annealing schedule of large 3-dimensional cast units is often based on practical experience. Based on the experience and furnace facilities of Poesia, the company concluded that each Crystal Houses brick with $65 \mathrm{~mm} \times 105 \mathrm{~mm} \times 210 \mathrm{~mm}$ dimensions requires approximately $8 \mathrm{~h}$ of annealing, whereas bricks of double the volume $(65 \mathrm{~mm} \times 210 \mathrm{~mm} \times 210 \mathrm{~mm})$
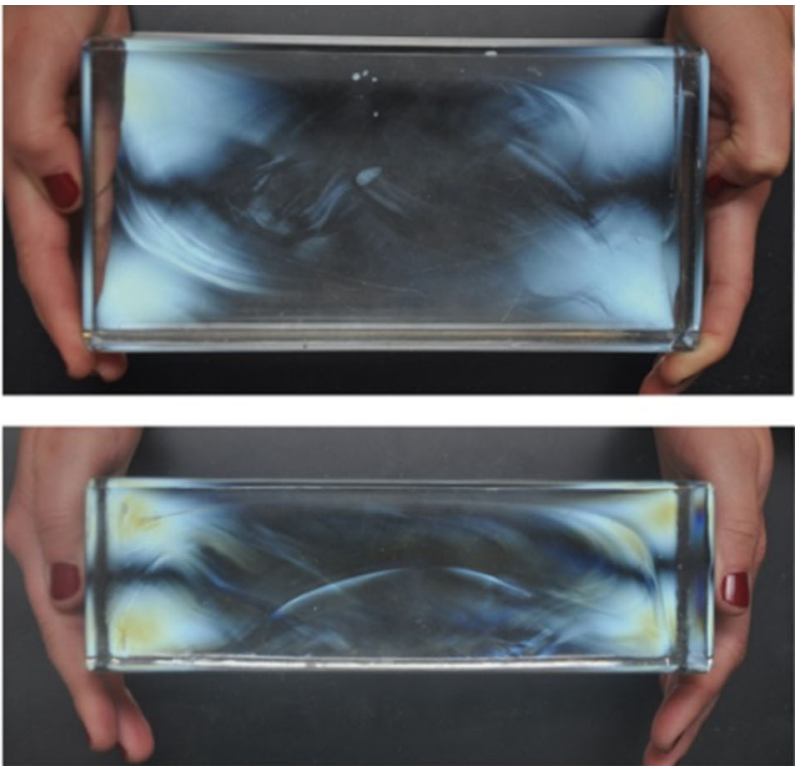

such as the one on the right, with no visible considerable strain concentration, were employed in the façade

require $36-38 \mathrm{~h}$ respectively to prevent the generation of attributable permanent residual stresses. The 65 $\mathrm{mm}$ thickness of the components hinders an accurate through-the-thickness stress measurement by a Scattered Light Polariscope (SCALP) stress-meter (using the current hardware/software). Instead a qualitative analysis of strain concentration was performed using a polarized white light source and a crossed polarized film that blocks the transmission of light. If glass is subjected to stress, it exhibits optical anisotropy. This corresponds to two refractive indices, which result in the presence of isochromatic fringes (coloured patterns) when polarized light passes through the component (see Fig. 9, left) (McKenzie and Hand 2011). Glass without any stress will appear completely dark (Schott AG 2004). If the specimen presents besides black only grey-scale spectral composition, ${ }^{3}$ it has low

\footnotetext{
${ }^{3}$ Shribak (2015) provides an extended analysis of the interference colours seen through polarization. For small retardance the brightness of the region increases, first with a white spectral composition at $200 \mathrm{~nm}$. As the retardance increases, colours start to appear beginning with yellow, then red, blue and green. The colour changes in this sequence three more times until the retardance reaches $2000 \mathrm{~nm}$. Then the interference colours turn white again and the retardance can no longer be reliably determined using the region's spectral composition. A continuous presence of only black and white subsequently signifies low residual stresses.
} 
Fig. 10 Glass bricks of 210 $\mathrm{mm} \times 210 \mathrm{~mm} \times 65 \mathrm{~mm}$ coming out of the annealing oven after circa $36-38 \mathrm{~h}$. The natural shrinkage is visible on the top surface

Fig. 11 Glass bricks rapidly cooled (prior to annealing) in vertical orientation. The natural shrinkage is evident besides the top surface, also along the larger surfaces
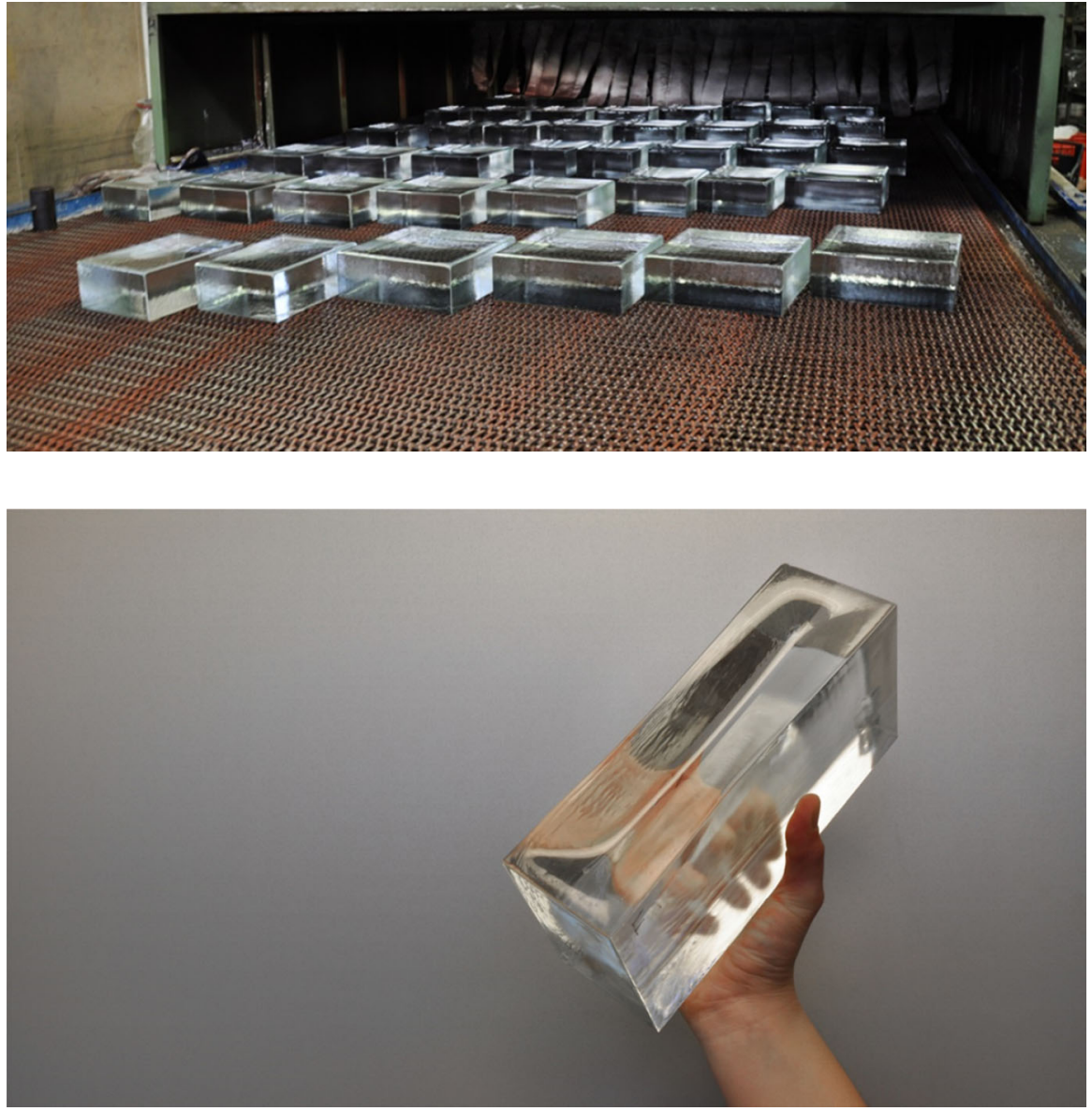

residual stresses. When the colour spectrum appears the amount of stress is higher but cannot be quantified. This method was used by Poesia to control all produced bricks. Bricks such as the one on the left of Fig. 9, with a clear indication of internal stresses by a coloured spectrum, were discarded. Only bricks such as the one on the right of Fig. 9, with dark and white areas were used in the façade. The fracture pattern of tested specimens also suggested low residual stressesthere was no excessive fragmentation observed in the components.

During the initial rapid cooling, natural, inevitable shrinkage occurs to the glass volume during the material's transition from liquid to solid state. The shrinkage causes different dimensions between units, uneven surfaces and is larger on the top, open surface of the casting component owing to the additional gravity force (see Figs. 6, 10).

Different casting orientations were tested for minimizing the resulting shrinkage in the larger, bonding surfaces of the bricks. Figure 11 demonstrates that even when molten glass is rapidly cooled in a vertical orientation, there is still visible shrinkage on the longer, bonding faces of the components.

As, regardless of orientation of the mould, the bricks' bonding surfaces required further processing, the horizontal position was favoured in terms of aesthetics, where the non-bonding sides are not visibly distorted. Thus, to achieve the desired $\pm 0.25 \mathrm{~mm}$ precision, the blocks are cast slightly higher. After the annealing process, a CNC machine mills the top layer of each block to remove the natural convex and obtain the precise height. Finally, both top and bottom faces of each block, i.e. the bonding surfaces, are polished to a smooth flat surface of the desired dimensional accuracy. The four vertical surfaces remain unprocessed as they do not influence the structural system. Mechanical testing on both CNC polished and unpolished bricks showed no deterioration of the mechanical properties of the former. 

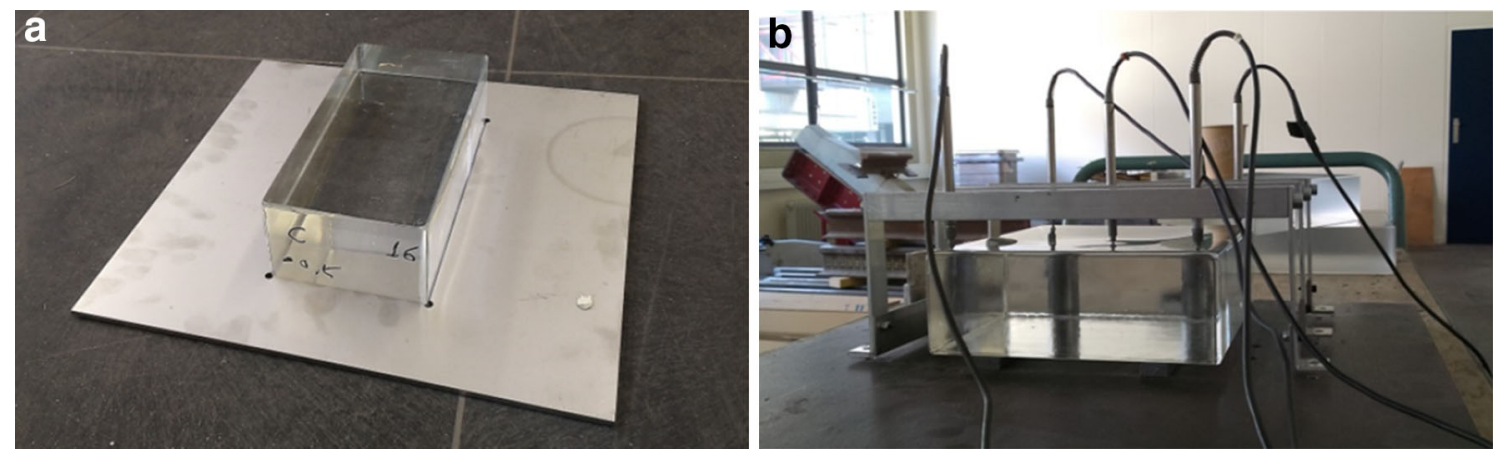

Fig. 12 a The jig used in the first dimensional control. b The set-up of the second control for checking the height and flatness of the components

The processed glass bricks are then subjected to two separate dimensional controls to verify their conformity. Both controls were performed first at Poesia and then again at $T U$ Delft for verification. The first control is accomplished by a cut-out metal plate jig that controls the total length and width of the brick in $1.00 \mathrm{~mm}$ accuracy (Fig. 12a). The second control employs a customized electromechanical measurement bench with five Linear Variable Differential Transformer (LVDT) sensors of $1 \mu \mathrm{m}$ accuracy (Fig. 12b) attached to an aluminium frame. By taking point measurements close to the four edges and at the center of each unit, the sensors check if the bricks meet the required $0.25 \mathrm{~mm}$ tolerance in both height and flatness from the nominal height of $65.00 \mathrm{~mm}$. It should be clarified that the range of acceptable height varies between 64.75 and 65.25 $\mathrm{mm}$ but within each particular brick the height deviation cannot exceed $0.25 \mathrm{~mm}$. Accordingly, through this measuring control, the acceptable bricks are sorted in two groups based on the point with the maximum height: Group A comprises bricks between 64.75 and $65.00 \mathrm{~mm}$ high and Group B comprises bricks between 65.00 and $65.25 \mathrm{~mm}$ high respectively. Only bricks of the same group were used per row of construction to maintain the $0.2-0.3 \mathrm{~mm}$ requirement for the adhesive thickness.

Besides the dimensional controls, a visual inspection of the bricks is performed as well at the construction site. Flaws at the bricks' bonding surfaces, usually in the form of minute cracks or scratches even less than $1 \mathrm{~mm}$ deep, commonly caused during the handling and transportation, can trigger the propagation of visible cracks after the adhesive's curing process. In specific, during curing the adhesive shrinks by $9 \%$
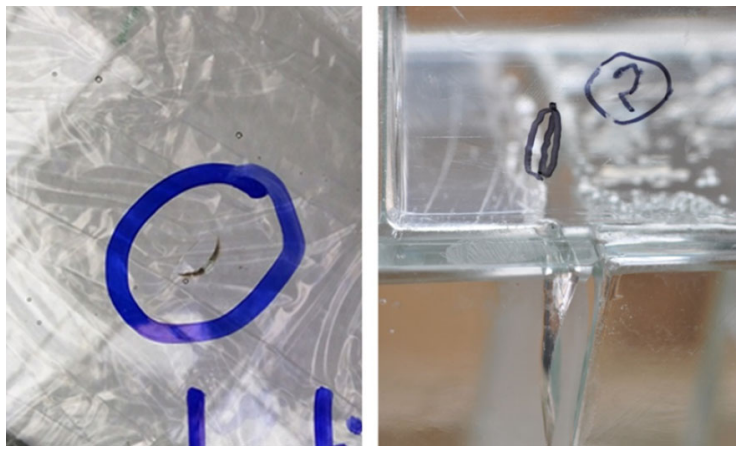

Fig. 13 Left: A minor crack on a brick's bonding surface. Right: The propagation of such a minor crack after the curing of the adhesive

vol at ambient temperature (Delo Industrial Adhesives 2014) because of polymerization triggered by UV-light (Delo Industrial Adhesives 2007), introducing a considerable amount of tension to the minute cracks that can start to propagate, eventually resulting in visible cracking (see Fig. 13). Only the glass components that pass both the measuring and visual controls were used in the construction of the façade.

\section{Construction of the glass brick wall}

\subsection{Construction site set-up}

The upper conventional masonry façade of the top residential floor, based on a steel beam spanning its length, was completed six months prior to the construction of the glass elevation (see Fig. 14). The level of complexity of the manual bonding process of the glass façade called for a highly skilled building crew 

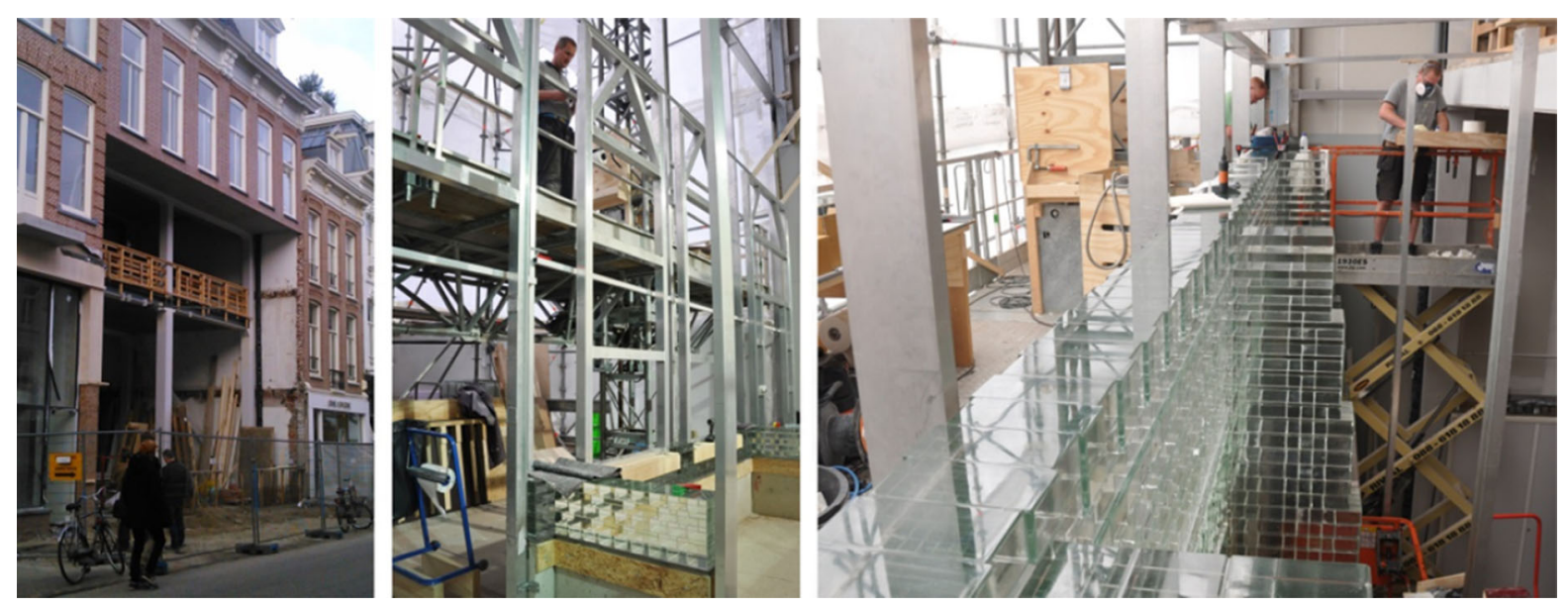

Fig. 14 Left: The masonry wall was already constructed prior to the glass elevation. Centre: the installed aluminium place holders of the opening. Right: The mast climbing working platform and one of the three mobile elevated platforms

and a strictly controlled construction. A $12 \mathrm{~h}$ working schedule was established, 5 days per week. Seven to nine highly skilled workers bonded and sealed on average $80-100$ bricks per day under the supervision of two quality control engineers and the construction site supervisor.

The special characteristics of the adhesive required the construction of the façade inside a UV-filtering tent for protection against solar radiation, adverse weather conditions and dust. To ensure a controlled level of temperature and humidity, heating equipment was installed inside the tent so that the bricks and the adhesive be maintained within workable temperatures during winter. During the summer, when the ambient temperature exceeded $30^{\circ} \mathrm{C}$ the construction would temporarily stop. Due to limited space in the construction site, the glass blocks were stored in pallets in a separate warehouse and were gradually transported to the site upon demand.

A scaffolding with a mast climbing working platform was installed for the construction of the glass brick wall (Fig. 14). Simultaneously, three mobile elevated working platforms were placed at the inner side of the wall for the construction of the buttresses. Bricks for one full row of construction were loaded and lifted each time on the mast climbing working platform, from where they were distributed for bonding. An elaborate network of horizontal aluminum guides was utilized to prevent any misalignment during the erection of the wall. Customized vertical aluminium frames were temporarily installed as place holders of the wall openings.

\subsection{Levelling the starting bonding surface}

The erection of the glass masonry wall started on top of a $0.60 \mathrm{~m}$ high by $0.20 \mathrm{~m}$ wide reinforced concrete plinth, essential for the protection of the lower part of the façade against hard body impact; it has been calculated to resist a vehicle collision travelling with a velocity of $50 \mathrm{~km} / \mathrm{h}$. To match the texture and color of the glass wall, the vertical faces of the concrete base are coated with a laminate of a stainless steel sheet and annealed patterned glass, laminated together by SentryGlas ${ }^{\circledR}$ foil. A $30 \mathrm{~mm}$ thick stainless steel plate fixed by bolts on top of the plinth, forms the base for the glass masonry wall (see Fig. 15).

The prerequisite for extreme accuracy of the developed glass block system necessitates a reference building surface of corresponding flatness. Accordingly, the stainless steel plate had to be levelled to an accuracy of $0.25 \mathrm{~mm}$ for the $12 \mathrm{~m}$ length of the façade. Such high measuring accuracy called for the development of an innovative measuring and levelling system. Specifically, the bolts, set $275 \mathrm{~mm}$ apart (see Fig. 15) allow for the levelling of the stainless steel plate in consecutive steps. By employing standard levelling equipment the plate is initially levelled to an accuracy of $3 \mathrm{~mm}$ over the $12 \mathrm{~m}$ length. Figure 16 demonstrates the principle 

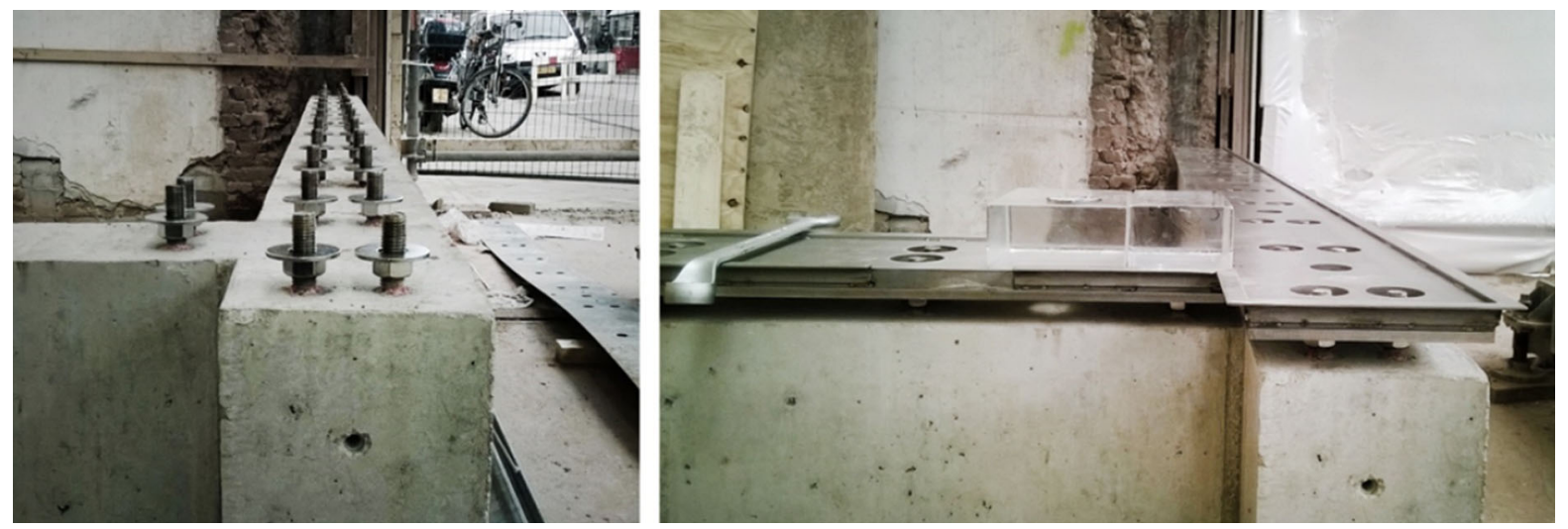

Fig. 15 On the left the bolts used for levelling the stainless steel plate, seen on the right

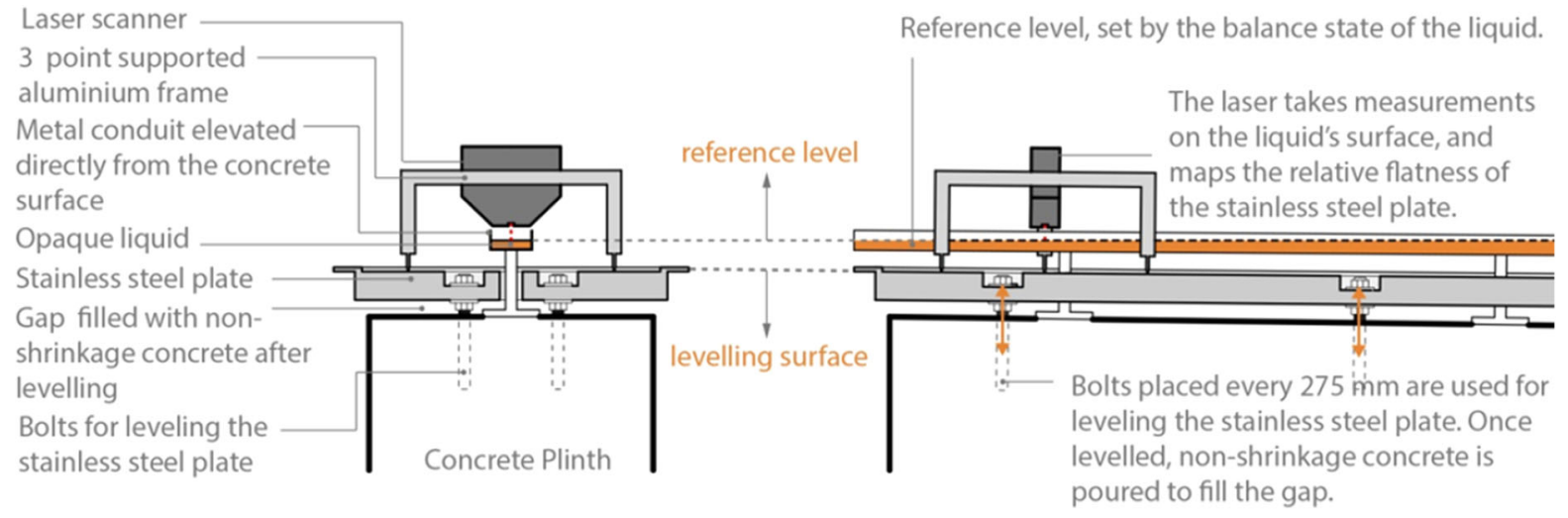

Fig. 16 Principle of the developed levelling system

of the measuring system developed to further level the stainless steel plate to the desired precision: A continuous open metal conduit with both ends sealed, supported directly on the concrete surface, is filled with a non-transparent liquid. When still, a liquid will achieve nearly absolute horizontal flatness, establishing the reference level for calibrating the plate. A laser scanner with a sensor of $1 \mu \mathrm{m}$ precision, fixed on an aluminium frame with three legs is then moved over a set of consecutive points on the stainless steel plate, taking measurements in reference to the liquid's surface, mapping the plate along its entire length. The use of an opaque reflective liquid (e.g. full fat milk) is essential for ensuring that the laser beam will take all measurements exactly at the same reference level. After the entire surface of the plate is mapped, by tightening or releasing the nuts and counternuts of the bolts the plate was successfully levelled with a maximum height devi- ation of $0.24 \mathrm{~mm}$ per total $12 \mathrm{~m}$ length. The resulting gap between the concrete base and the plate was filled with non-shrinkage concrete and left to cure.

\subsection{Bonding}

The $0.2-0.3 \mathrm{~mm}$ optimum thickness of the adhesive layer demanded extreme precision in each construction layer. In traditional terracotta brickwork the mortar plays the dual role of bonding and accommodating tolerances in the size of the bricks. However, the selected adhesive's inability to compensate for any dimensional discrepancies in the construction can result to an accumulated offset of a few centimeters in the total height of the façade, even when the allowable tolerance per glass component is only $\pm 0.25 \mathrm{~mm}$. To eliminate the development of fluctuations in the height of the con- 

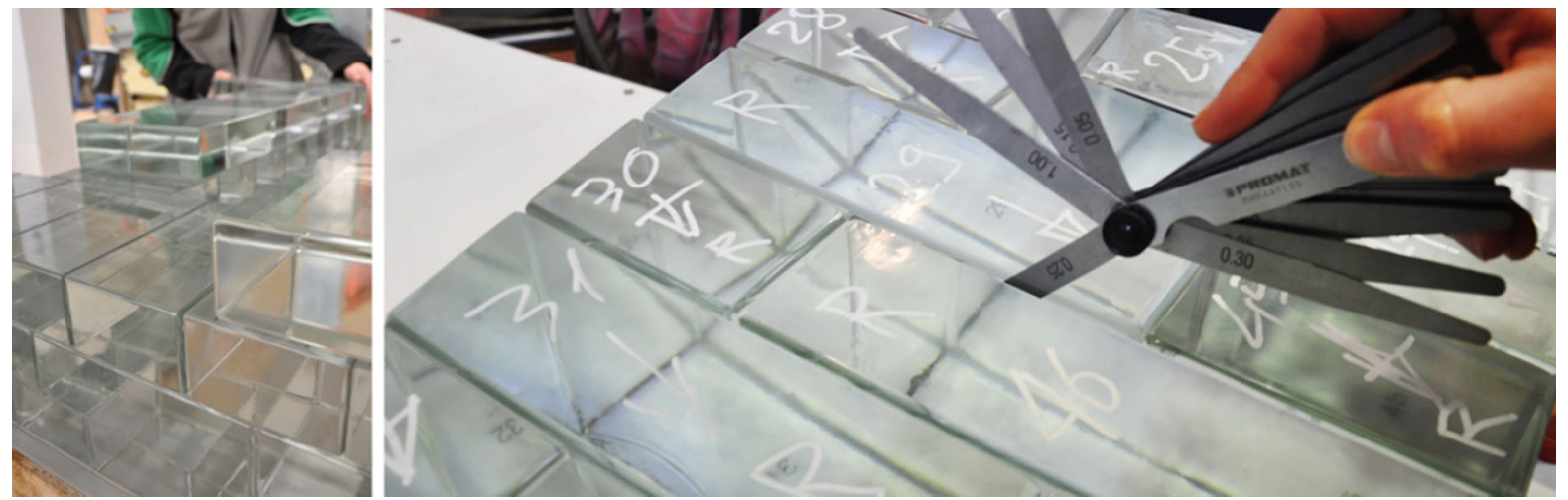

Fig. 17 Bricks of a new row laid down prior to bonding (left). Then a feeler gauge is used for checking the thickness of the resulting seam (right). The blade of the feeler gauge is sufficiently flexible and round not to induce any surface damage on glass
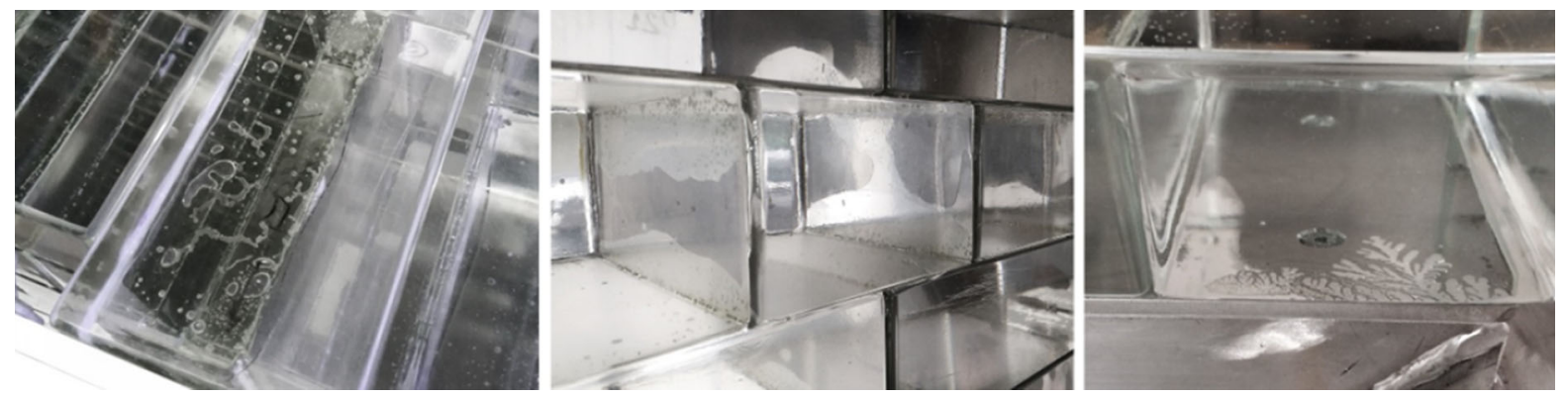

Fig. 18 Common flaws occurring in the adhesive layer: air gaps, capillary action and dendroid patterns

struction, all the glass bricks of a new row are laid down prior to bonding. The thickness of the resulting horizontal joint between the laid bricks and the bonded ones below is then checked by a feeler gauge (see Fig. 17). When the seam is larger than the suggested $0.25 \mathrm{~mm}$, the corresponding brick is replaced with another one that accomplishes better contact in the specific location. The final selection of bricks is then numbered to guarantee their correct bonding sequence.

Previous structural and visual tests by Oikonomopoulou et al. (2015b) suggested the bonding of the complete contact surface between blocks. The uniform application of the adhesive besides ensuring a homogeneous load distribution, is also essential for maximizing transparency. Indeed, the façade's visual result is deeply affected by any form of air gaps and bubbles in the adhesive layer, as well as from stains caused by the adhesive's overflow or capillary action (see Fig. 18). To eliminate such defects a customized bonding procedure was applied.

Initially, the bricks are visually inspected on site for any defects, as explained in chapter 3 . Then, the sur- faces to be bonded are cleaned with 2-propanol. Specially designed self-reinforced polypropylene forms out of PURE ${ }^{\circledR}$ (DIT 2016) are placed for the distribution of the adhesive in an $\mathrm{X}$ pattern, controlling the flow, spread and amount of the adhesive (see Fig. 19). To prevent any capillary effect along the vertical faces of the glass bricks, a special, UV beam light is used to locally harden the liquid adhesive in case it arises on the vertical seams.

Once the adhesive is evenly spread, it is initially exposed to low intensity UV-light for $5 \mathrm{~s}$ while the brick is kept in position and under pressure. This pre-curing step was introduced for practical reasons ${ }^{4}$ as this partial curing stabilizes the glass brick while still allowing the wiping-off of any adhesive overflow. After cleaning, the adhesive is further cured by low and medium intensity UV-radiation in the range of $20-60 \mathrm{~mW} / \mathrm{cm}^{2}$ and for a period of 60-120 s, according to brick size. Once

\footnotetext{
$\overline{4}$ This pre-curing time was set experimentally. Testing of specimens cured in this way did not reveal any differences with specimens cured once off.
} 

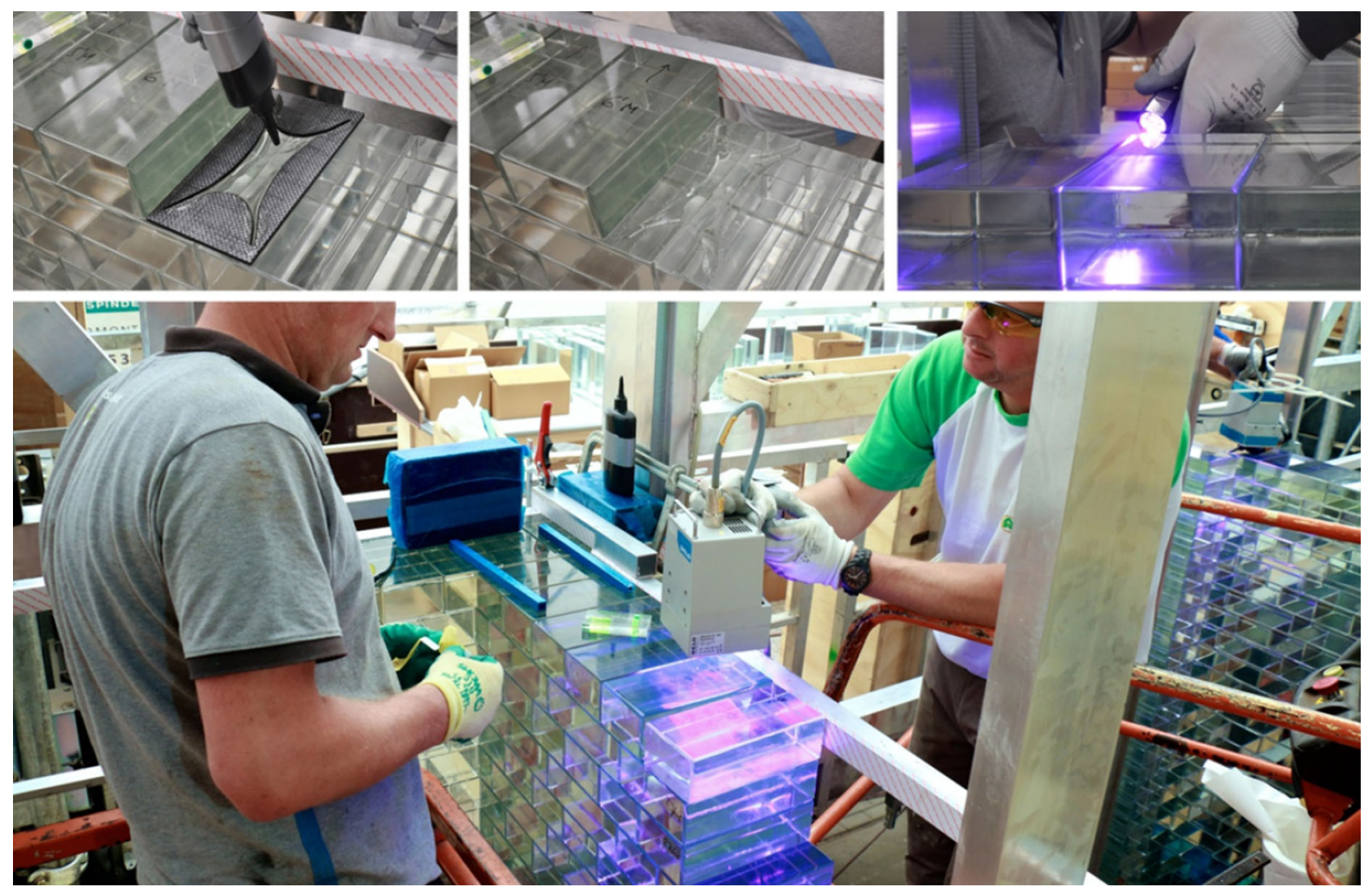

Fig. 19 Bonding steps from left to the right: 1. Application of the adhesive with the aid of the PURE ${ }^{\circledR}$ form. 2 . Resulting $\times$ pattern. 3. Local hardening of the adhesive by a UV beam light for preventing capillary action. 4 . UV-lamp used to cure the adhesive for $60-120 \mathrm{~s}$ a complete brick layer is bonded, all joints are sealed in order to guarantee the dust, water- and moisturetightness of the façade. For the sealing, Delo Photobond 4497 (Delo Industrial Adhesives 2016b), a more flexible and viscous, clear UV-curing Delo-Photobond acrylate, specially designed for outdoor applications, is selected due to its good visual performance, compatibility with Delo-Photobond 4468 as well as for its easy and quick application (see Fig. 20). This adhesive requires only $10 \mathrm{~s}$ of UV-curing to be completely hardened.

The first row of glass blocks was directly bonded onto the stainless steel base by Delo-Photobond 4468. As previously mentioned, Delo Photobond 4468 is recommended by the manufacturer for glass to metal bonding as well. Previous research on such a bond has been conducted by Puller and Sobek (2008). The established rigid connection was considered imperative by the structural engineers in order to eliminate any horizontal movements of the free-standing façade. Any movements due to temperature strains in the structure are compensated by the flexible connections at the sides and top of the façade (see Chap. 4.6).

Every $2 \mathrm{~m}$ of elevation, the levelling along the total length of the façade is recorded using a high accuracy total station. Bricks with a 0.5 or $1.0 \mathrm{~mm}$ reduction in height were specially manufactured for the levelling of the wall in case of height deviations. Such bricks were required to level the wall segments when reaching the level of the architraves of the ground and first floor. At the top of the elevation, the glass wall is connected to a steel beam by a $22 \mathrm{~mm}$ thick structural modified silane (MS-) polymer bond. This flexible connection can accommodate displacements due to the different thermal expansion and stiffness between the upper construction and the glass wall. A flexible waterproof tube filled the gap towards the interior of the wall, to further prevent water leakage. As ceramic strips cover the entire top row, the connection details are fully hidden (Fig. 21). 

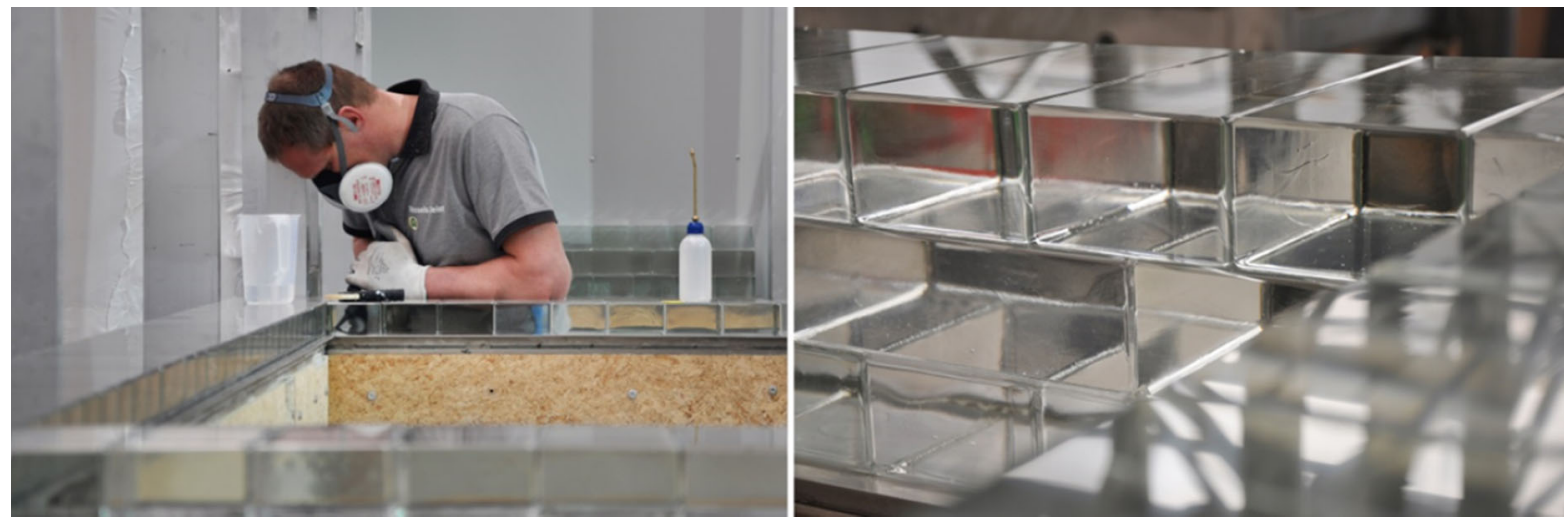

Fig. 20 Left: Sealing of the already bonded bricks. Right: the final, visual result achieved by the novel bonding method
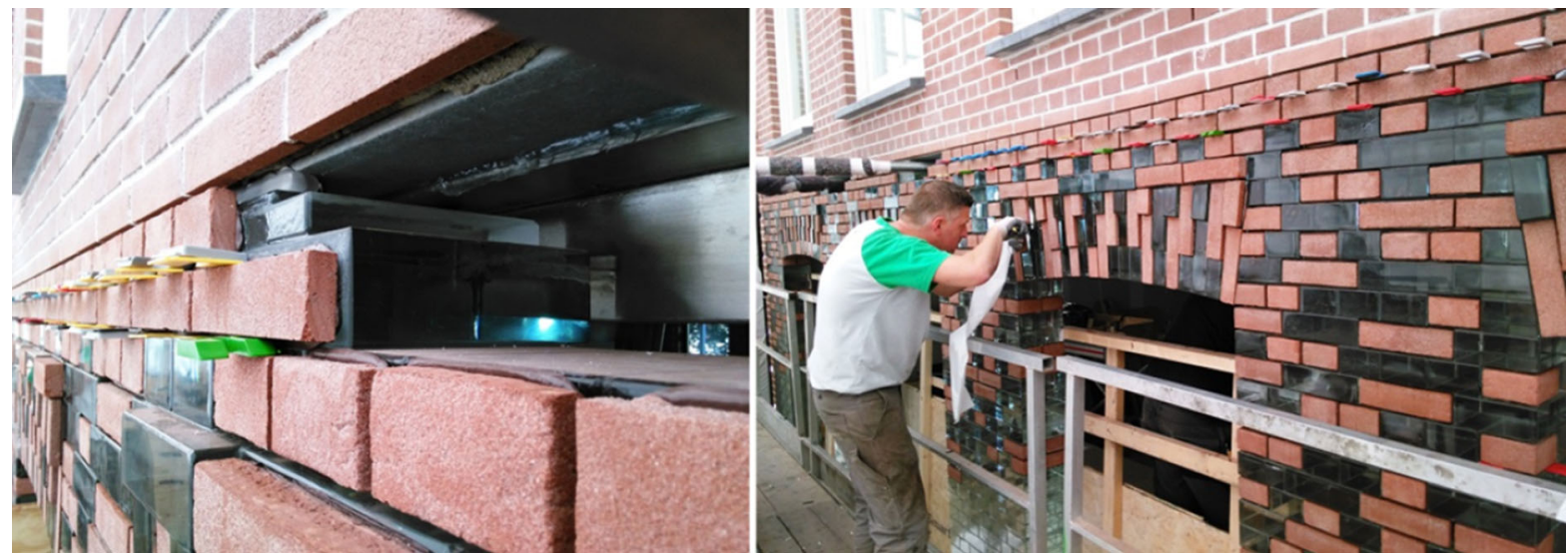

Fig. 21 The top connection is completely masked by the ceramic strips

\subsection{Construction and installation of the architraves}

The architraves above the window and door openings of the original nineteenth century elevation are also reinterpreted into glass components by special tapered glass bricks bonded together by the same adhesive along their vertical surfaces. Due to the medium viscosity of the Delo Photobond 4468 each architrave had to be pre-assembled into one single component in a custom made rotating steel fixture. The rotating fixture ensures the horizontal application of the adhesive, as well as the desired arch geometry, with a straight top line in accordance to the maximum $0.25 \mathrm{~mm}$ deviation rule. The finished components, fabricated in the TU Delft Glass \& Transparency Lab, were then transported on site and installed one by one in situ with the aid of a jib fixture on the fork lift, as shown in Fig. 22.

\subsection{Transition layer between standard and glass masonry}

To obtain a smooth, gradual connection to the standard brickwork of the final, residential floor of the building, the initial intention of the architects was to realize a transition zone of intermixing glass and normal terracotta bricks towards the top of the façade. Nonetheless, the structural blend of the two materials presented various practical implications, as can be seen in Fig. 23. Besides having different mechanical properties, the two types of bricks vary appreciably in acceptable tolerances. While in the glass bricks the required precision in height is $\pm 0.25 \mathrm{~mm}$, for the terracotta bricks is at least $\pm 1.0 \mathrm{~mm}$. Most importantly, the bonding between the two brick types necessitates the application of different adhesives, involving the risk of their intermixing. Lastly, the strongly alkaline character of most mortars 

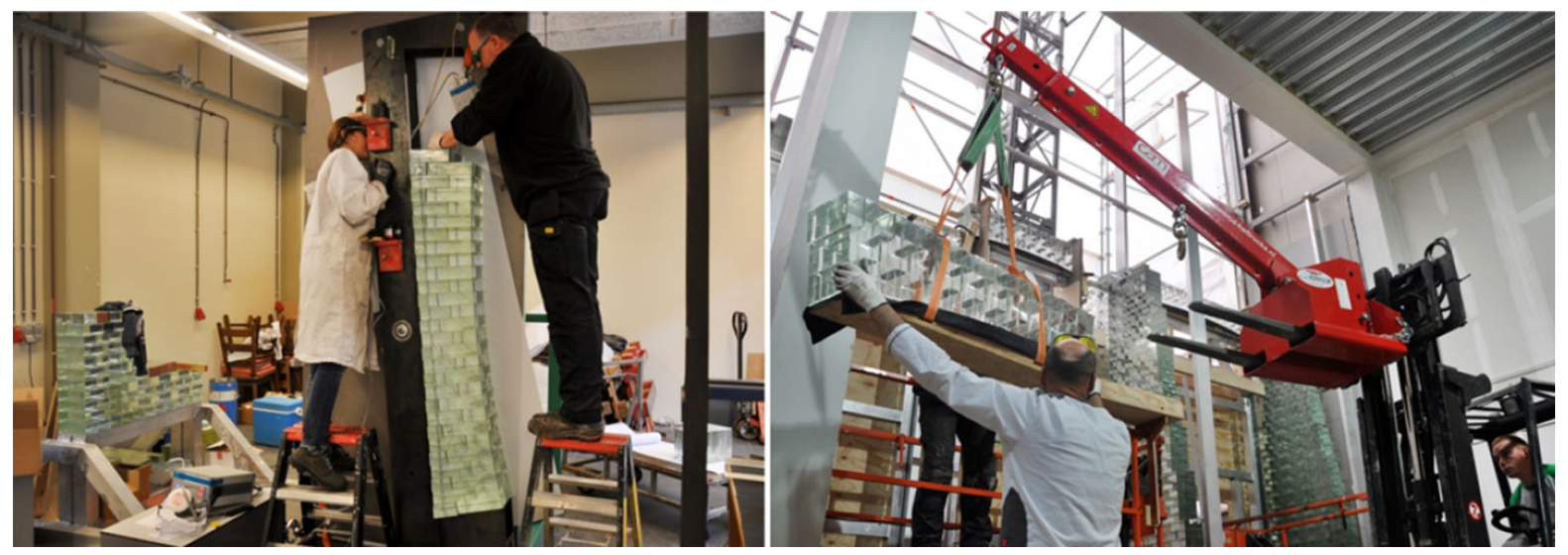

Fig. 22 Left: The special rotating fixture for the preassembly of the architraves. Right: The installation of the bonded architraves on site

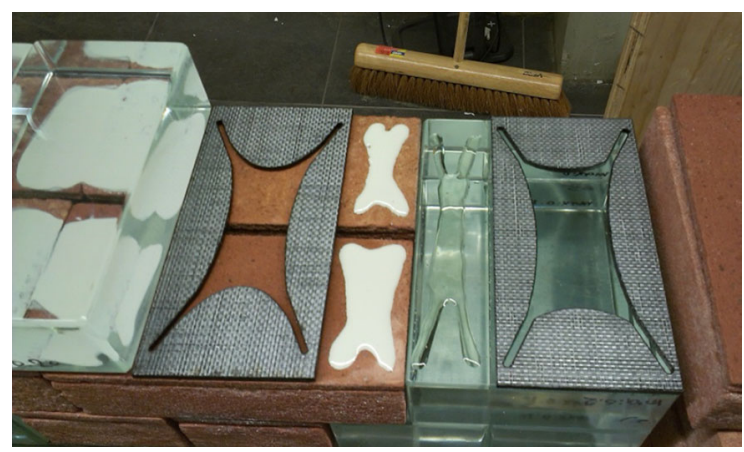

Fig. 23 Practical implications encountered when combining terracotta and glass blocks, such as differences in acceptable tolerances and in use of adhesives

used for the bonding of standard ceramic bricks attacks the glass surface and must be avoided. It should be mentioned that, as the upper conventional masonry façade was completed six months prior to the construction of the glass elevation and the mortar was fully cured, there was no hazard of alkaline reaction between the mortar and glass.

Due to all the aforementioned reasons the option of combining terracotta and glass was discarded. Instead the following solution was applied: Glass bricks, 40 $\mathrm{mm}$ shorter in width, clad with an $18 \mathrm{~mm}$ thick ceramic strip at each external side, replace the traditional bricks in the intermixing zone. The ceramic strips are bonded on the façade after all glass blocks have been bonded in place, preventing the occurrence of adhesive stains on their exterior surface. Tec 7 (Novatech 2016), a brown coloured modified silane polymer is applied for bonding the strips to the glass units. With an application thickness of circa $3 \mathrm{~mm}$ the adhesive compensates for any difference in thermal strains between the two materials. Once all the ceramic strips are bonded to the façade, the seams around the strips and the glass are sealed by Zwaluw Joint Fix $310 \mathrm{ml}$ lichtgrijs (Den Braven 2017), an acrylic based mortar of similar texture and color to the mortar used for building the wall above (see Fig. 24). The selected mortar is less brittle than normal mortar due to its acrylic content and features considerably less volume shrinkage (5\%) (Den Braven 2017) after hardening in comparison to standard mortar types, preventing thus its delamination from the glass blocks. The completed intermixing, gradient zone can be seen in Fig. 25.

\subsection{Boundary connections of the façade}

The façade forms a free standing wall firmly connected to the concrete plinth. To allow for displacements due to the different thermal expansion and stiffness between the glass wall and its boundaries, the façade is joined via flexible connections to the top metal beam, supporting the residential level above, and to the stainless steel columns on the vertical sides. The top connection of the two structures is realized by a modified silane (MS-) polymer adhesive bond as analyzed in Chap. 4.3.

Regarding the connection along the vertical sides, this varies between the right and left (as seen from the street) side of the wall at the ground floor, since the left side is self-supported by a buttress. On the right side at 

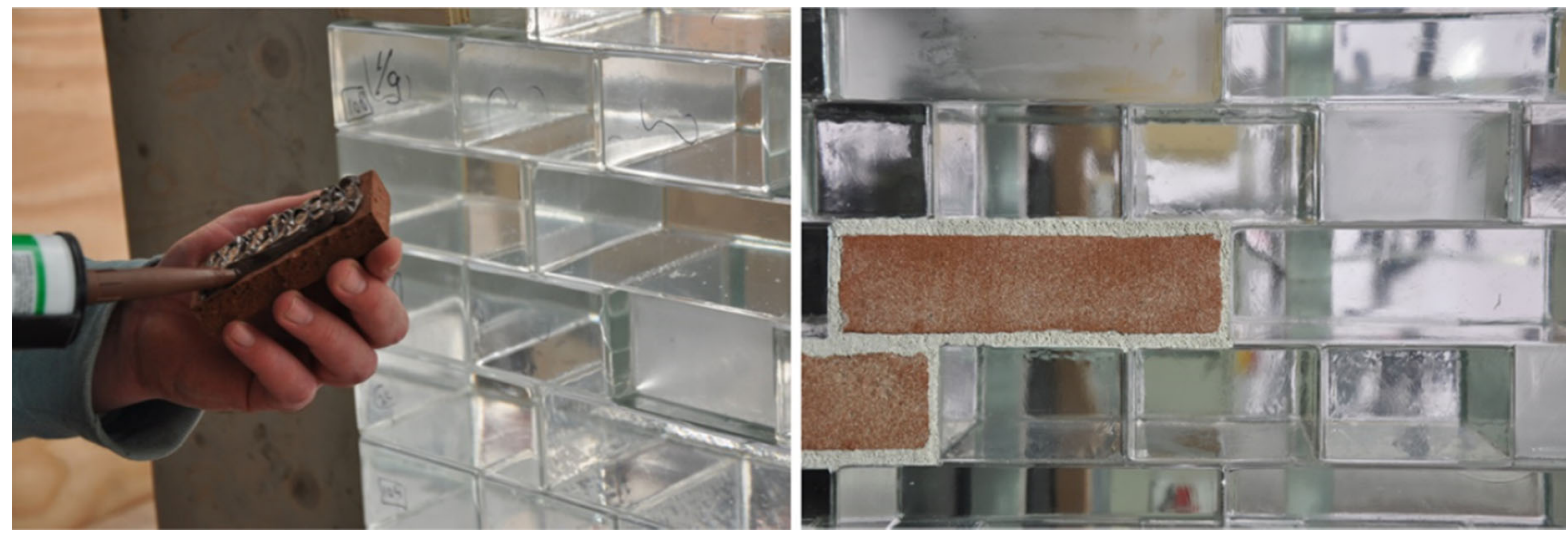

Fig. 24 Left: Bonding of the ceramic strips to the shorter bricks. Right: The final visual result after the ceramic strips have been sealed

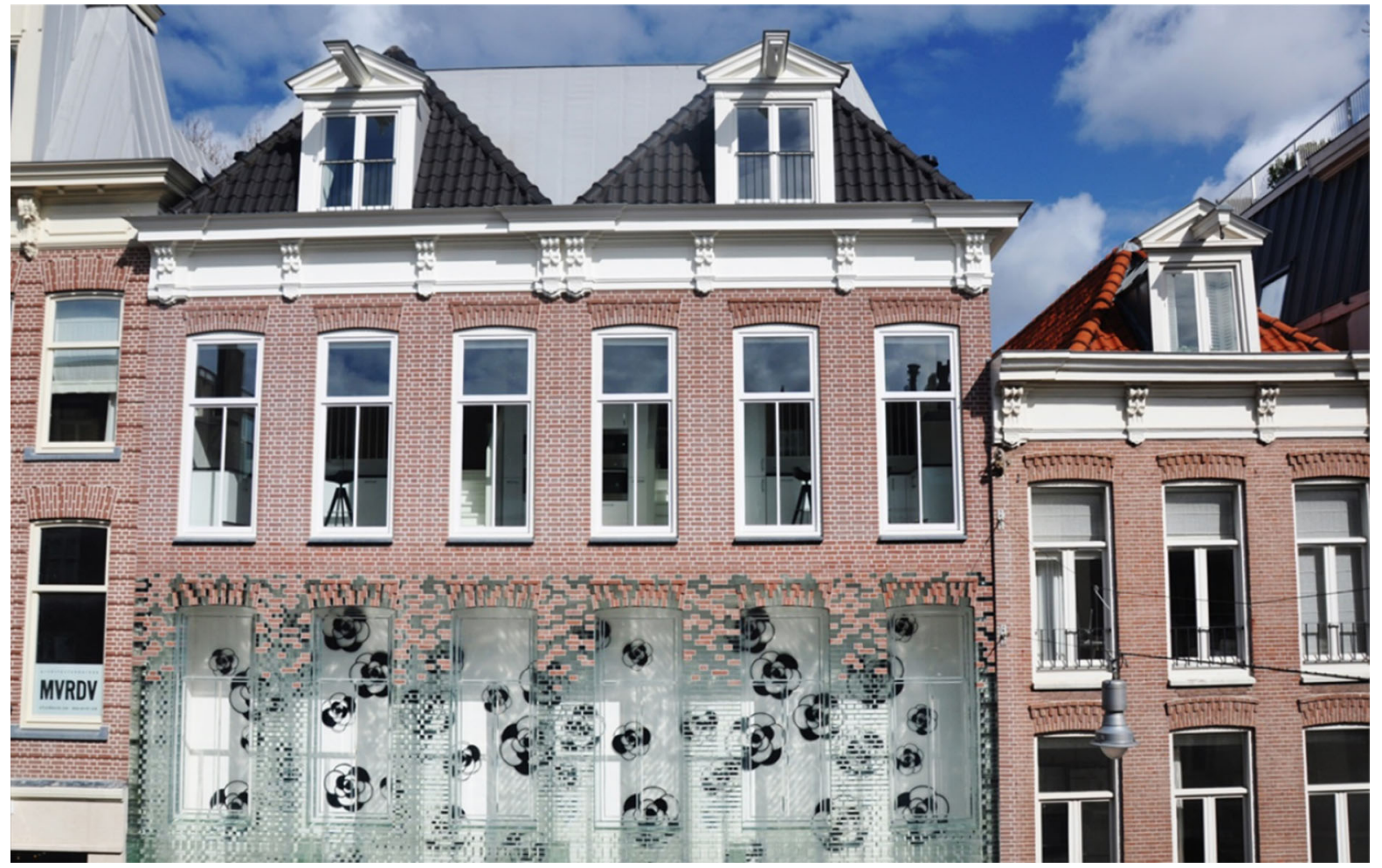

Fig. 25 End result of the intermixing, gradient zone

the ground floor, as well as on both sides at the first floor, the glass masonry wall is connected by a $10 \mathrm{~mm}$ thick layer of a clear silyl-terminated semi-elastic polymer to the stainless steel L-shaped columns to compensate for thermal displacements of the wall. Since for the curing of the specific MS-polymer adhesive the contact with atmospheric conditions is essential, the adhesive was applied gradually with a glue-kit dispenser using compressed air row by row, so that each glue layer can set until the next row of bricks is completed (see Fig. 26). The bricks at the right side of the ground floor are each clad with two $1 \mathrm{~mm}$ thick stainless steel strips at their adjacent to the L-shaped column sides, to mask the rough detailing of the welded stainless steel structural 

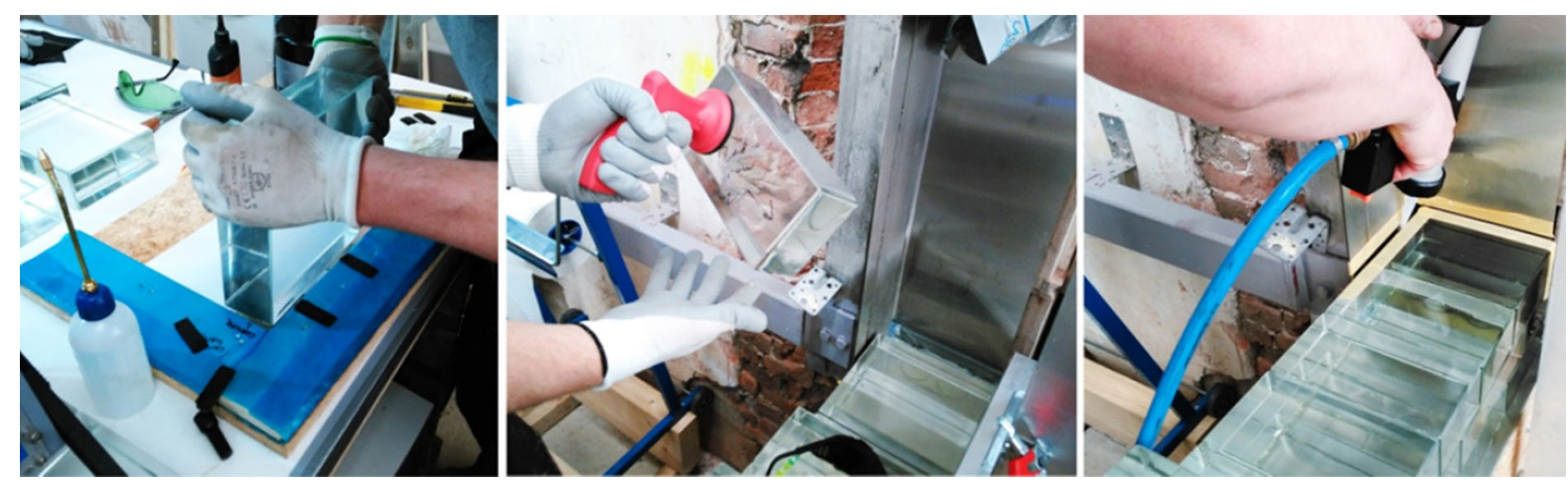

Fig. 26 From left to right: Bonding of the steel plate to the corner brick. Positioning of the brick by a suction cup holder. Application of the semi-elastic polymer

Fig. 27 The graphite moulds used for the fabrication of the frames
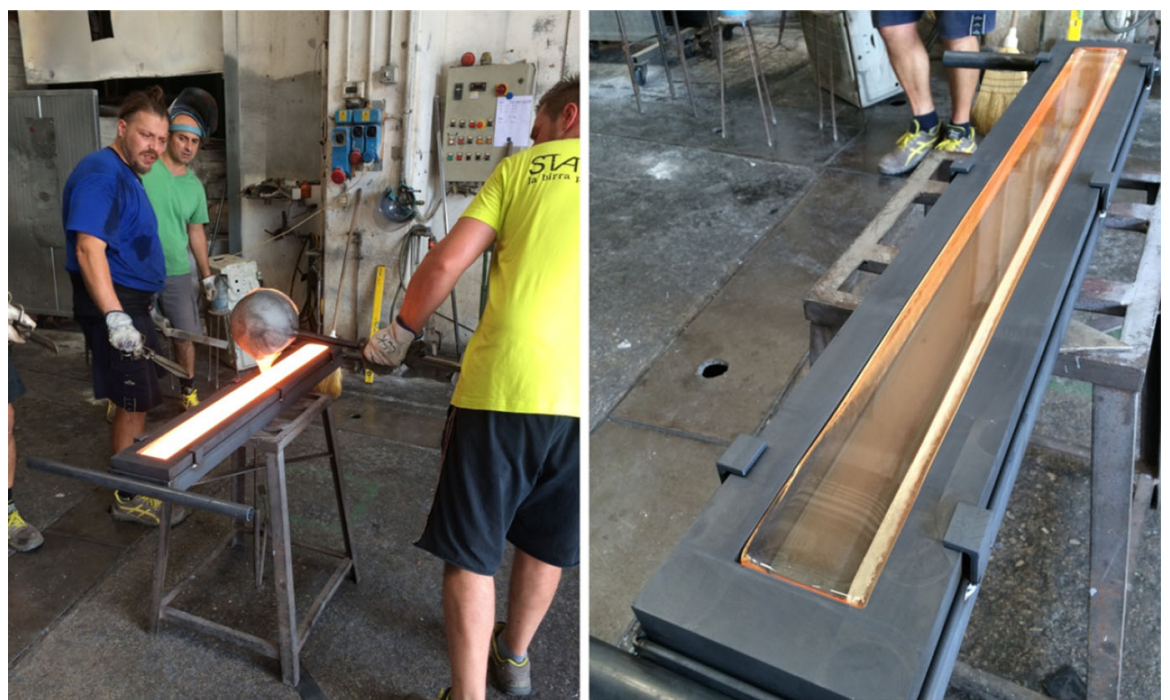

components (see Fig. 26). The cladding is applied to the bricks prior their bonding to the façade. For such a connection, DELO Photobond 4497 is used, to ensure impact resistance.

\subsection{Installation and bonding of the cast glass window and door frames}

The reproduction of the previous, historic elevation's wooden openings in cast glass was an extra challenge added to the engineering and construction of the Crystal Houses as it included the manufacturing and bonding of massive cast glass elements. The glass frames were cast by Poesia in open graphite moulds (see Fig. 27), ground along their open surface to remove the mate- rial shrinkage layer and polished with a rotational band manually. As such pieces present larger tolerance problems, DELO Photobond 4494 (Delo Industrial Adhesives 2016a) was chosen to bond the frame elements together due to its higher viscosity and application thickness that allow for easier tolerances, while maintaining a clear optical result. This adhesive has a comparatively lower mechanical resistance to Delo Photobond 4468, yet sufficient for integrating the glass frames into the construction.

The window and door frames were placed after the completion of the glass wall. During the bonding process, aluminum place holders were used to secure temporarily the location of the openings. First each frame was assembled in place by DELO Photobond 4494. Based on the UV-measurements per $\mathrm{m}^{2}$ done by Siko 

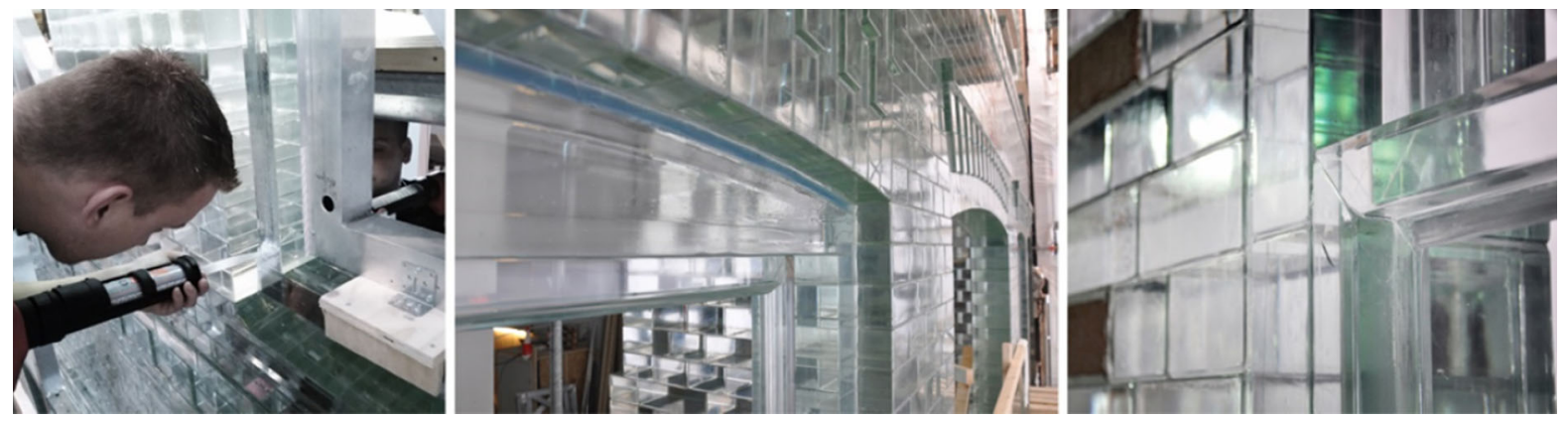

Fig. 28 Left: The simultaneous application of the polymer from both sides. Centre and right: The final result of the bonded glass frames

b.v. the sill of each window frame, of $1145 \mathrm{~mm} \times$ $143 \mathrm{~mm}$ footprint, required 4 minutes of total curing by two UV-lamps travelling back and forth along its length.

Once the frame was in place, the side and top connection to the glass masonry wall was established. The thickness of this connection was designed to be $8 \mathrm{~mm}$, to compensate for horizontal and vertical deviations in the glass masonry wall, and was achieved by the same clear silyl-terminated semi-elastic polymer used also at the top and side connections of the wall. To avoid the entrapment of air, the polymer was injected at both sides simultaneously from bottom to top (see Fig. 28). After a few days, when the polymer had reached a satisfactory strength, the aluminium frames were removed. Then the cast glass mullions were bonded to the glass frames via the same polymer applied in a $2 \mathrm{~mm}$ thick layer. Finally, the glass panes were bonded to the mullions by a standard transparent silicone, completing the façade. The end result can be seen in Fig. 28.

\section{Conclusions}

A novel, completely transparent self-supporting glass masonry wall system has been developed and realized through pioneering research in the Crystal Houses façade (Fig. 29). With the exclusive use of solid cast glass elements bonded together by a clear, high stiffness, adhesive and with the aid of geometry for enhancing the lateral stability, the $10 \mathrm{~m}$ by $12 \mathrm{~m}$ façade combines the desired structural performance with pure transparency. The façade is capable of carrying its own weight and withstanding wind loads without any additional substructure when the adhesive-glass assembly functions as one rigid unit under loading. Previous experimental work by Oikonomopoulou et al. (2015b) indicated Delo Photobond 4468, a one-component, UV-curing acrylate for attaining both the desired monolithic structural performance and high transparency level. The experiments also demonstrated that the desired structural and visual performance is only guaranteed when the adhesive is applied in a uniform layer of a mere $0.2-0.3 \mathrm{~mm}$ thickness. This in turn leads to an allowable dimensional tolerance of a quarter of a millimetre in the height and flatness of the cast glass components. This demand of extreme dimensional precision introduced new challenges in the engineering of the façade from the manufacturing of the bricks to their bonding method, calling for pioneering solutions.

Due to the inevitable natural shrinkage of molten glass, such dimensional accuracy could only be attained by CNC-cutting and polishing of the bricks' horizontal faces to the desired height. Soda-lime glass and open, high precision moulds were preferred over borosilicate glass and press moulds to reduce the manufacturing cost. Special measuring equipment was developed for controlling the dimensional accuracy of the components.

Nonetheless, even blocks of such high dimensional accuracy can still lead to a significant offset in the façade's total height. The fundamental difference between a conventional brickwork and the developed glass masonry system is that a standard mortar layer compensates for deviations in the size of the bricks, while the selected adhesive cannot. This manifests the level of complexity deriving from the manual bonding and the significance of constantly controlling the entire construction with high precision methods.

A completely transparent façade is moreover linked with the inability to hide any possible flaws in the construction. The development of a novel bonding method 


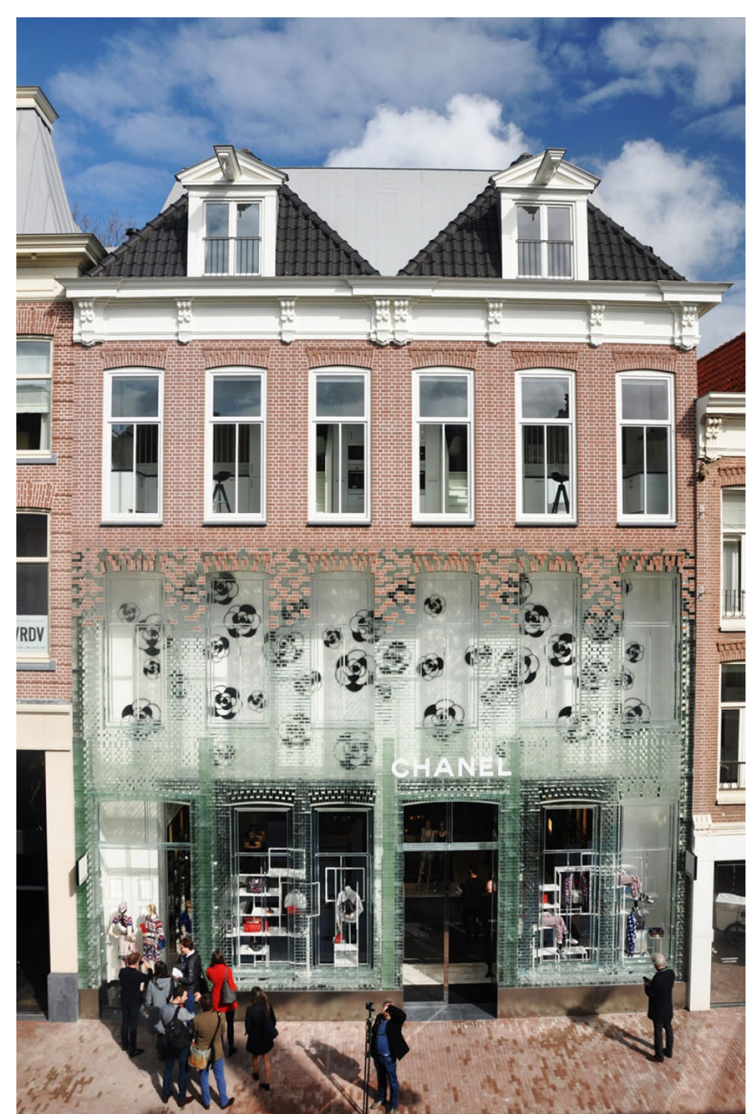

Fig. 29 The completed Crystal Houses façade

for the homogeneous and flawless application of the adhesive resulted in imperceptible connections in the constructed façade.

\section{Discussion and further research}

Overall, the innovative glass masonry system developed for the Crystal Houses façade illustrates the great potential of adhesively bonded cast glass blocks as an answer to the quest of structural transparency and can form the basis for novel architecture applications. The system can be further engineered in order to simplify and accelerate its application, minimize the interlinked challenges and decrease the cost.

Most of the engineering puzzles elaborated in this paper can be solved with the use of a thicker transparent adhesive of equal structural performance that in turn can allow for larger tolerances.

In this direction, different envelope geometries can enhance the rigidity of the structure, allowing for thicker, more elastic adhesives and correspondingly for larger tolerances in the brick units.

Moreover, the development of a casting method of glass units of higher accuracy without the need of postprocessing would significantly facilitate the entire production and building process as well as enhance the structural and architectural result.

Likewise, the choice of glass recipe plays a crucial role in the total annealing time and in the scale of resulting natural shrinkage. Although a faster and more accurate casting process can be achieved with borosilicate glass instead of soda-lime, the total manufacturing cost and dimensional precision prerequisites should be considered prior to the glass recipe choice.

Lastly, the casting of glass units can provide the designer with a great freedom in the shapes and sizes

Fig. 30 Interlocking, dry-assembly glass bricks developed by

Oikonomopoulou,

Bristogianni and Barou for the 3TU.bouw Lighthouse project: Restorative Glass

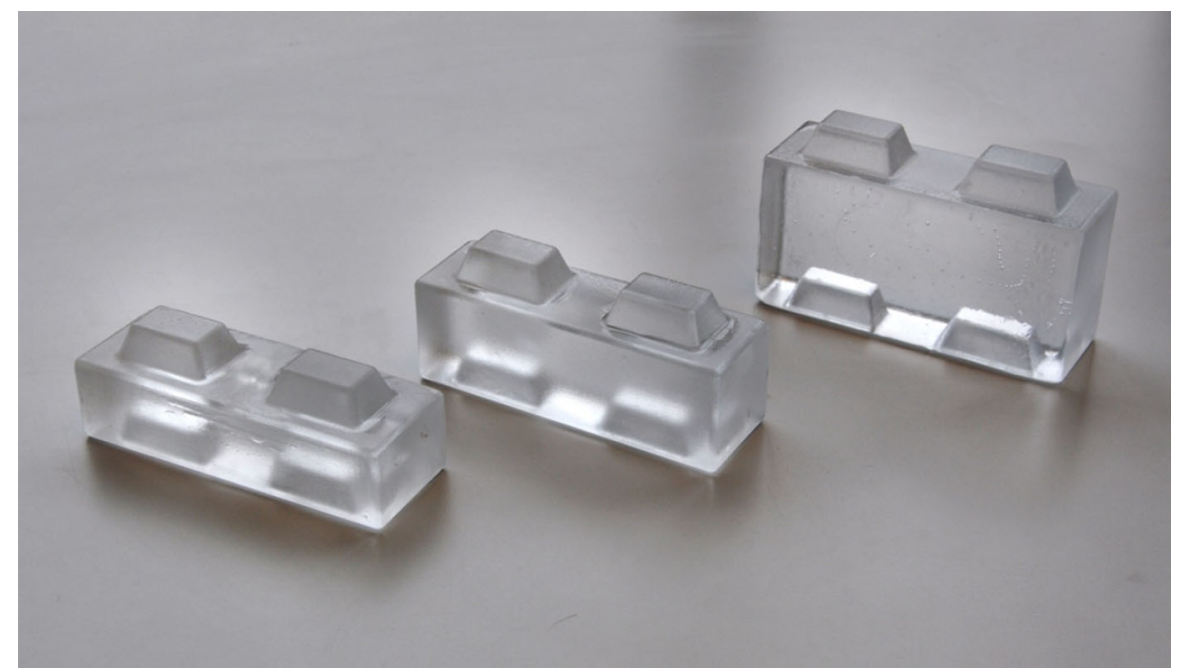


of the masonry module. A promising solution for all transparent, load-bearing glass structures is the development of interlocking cast units. Currently, research is being conducted by the authors on the development of such a system that circumvents the use of adhesives by employing dry connections instead (see Fig. 30). In this case, the overall stability is attained by the total weight of the construction in combination with the unit's interlocking geometry that provides the necessary constraints against lateral movement. To prevent stress concentrations due to the high contact pressure between the glass elements, a transparent foil is placed as an intermediate layer between the units, allowing as well for dimensional tolerances in the cast components' size.

Acknowledgements The research work was conducted by the TU Delft Glass \& Transparency Lab for AshendeneLeeuwenstein BV whose permission to publish the results is gratefully acknowledged. MVRDV and Gietermans \& Van Dijk are responsible for the architectural design, ABT b.v. for the structural simulations, Wessels Zeist b.v. for the construction of the Crystal House façade and Poesia Ltd. for the manufacturing of the glass bricks. We thank Ashendene-Leeuwenstein BV and MVRDV for the 3-D impressions of the case study. We especially want to thank Rob Janssen from Siko BV for his valuable advice and assistance. Ruud Hendrikx at the Department of Materials Science and Engineering of the Delft University of Technology is acknowledged for the X-Ray analysis.The authors gratefully acknowledge Kees Baardolf and Kees Van Beek for their invaluable technical assistance and insight throughout the project.

\section{Compliance with ethical standards}

Conflict of interest On behalf of all authors, the corresponding author states that there is no conflict of interest.

Open Access This article is distributed under the terms of the Creative Commons Attribution 4.0 International License (http://creativecommons.org/licenses/by/4.0/), which permits unrestricted use, distribution, and reproduction in any medium, provided you give appropriate credit to the original author(s) and the source, provide a link to the Creative Commons license, and indicate if changes were made.

\section{References}

Corning Museum of Glass: Types of Glass. http://www.cmog. org/article/types-glass (2011)

Crocombe, A.D.: Global yielding as a failure criterion for bonded joints. Int. J. Adhes. Adhes. 9(3), 145-153 (1989)

da Silva, L.F.M., Rodrigues, T.N.S.S., Figueiredo, M.A.V., de Moura, M.F.S.F., Chousal, J.A.G.: Effect of adhesive type and thickness on the lap shear strength. J. Adhes. 82(11), 1091-1115 (2006)
Delo Industrial Adhesives: Bond it: Reference Book on Bonding Technology, 2nd edn. Delo Industrial Adhesives, Munich (2007)

Delo Industrial Adhesives: Glass Bonding: Requirements. Product Range and Design Examples. In. Delo Industrial Adhesives, Munich (2011)

Delo Industrial Adhesives: Technical Information: DeloPhotobond 4468. Delo Industrial Adhesives, Windach (2014)

Delo Industrial Adhesives: Delo Photobond 4494 Technische Information. In. Delo Industrial Adhesives, Windach (2016a)

Delo Industrial Adhesives: Delo Photobond 4497 Technical Information. Delo Industrial Adhesives, Windach (2016b)

Den Braven: Zwaluw Joint Fix Technische datasheet. In: Den Braven (ed.). Oosterhout (2017)

den Ouden, G.: Lastechnologie. VSSD, Delft (2009)

DIT b.v.: Pure-Technical Data Sheet. In: DIT b.v. (ed.). Dinxperlo (2016)

Fink, A.: Ein Beitrag zum Einsatz von Floatglas als dauerhaft tragender Konstruktionswerkstoff. Technische Universität Darmstadt, Ph.D. (2000)

Grant, L.D.R., Adams, R.D., da Silva, L.F.M.: Experimental and numerical analysis of single-lap joints for the automotive industry. Int. J. Adhes. Adhes. 29(4), 405-413 (2009)

Granta Design Limited: CES EduPack 2015. Granta Design Limited, Cambridge (2015)

International Organization for Standardization: ISO 21690:2006 (en). In: Glass in Building-Glass Blocks-Specification and test methods. ISO (2006)

McKenzie, H.W., Hand, R.J.: Basic Optical Stress Measurement in Glass. Society of Glass Technology, Sheffield (2011)

MVRDV Architects: Crystal Houses. https://www.mvrdv.nl/en/ projects/crystal-houses (2016). Accessed 21 Feb 2017

Napolitano, A., Hawkins, E.G.: Viscocity of a standard sodalime-silica glass. J. Res. Natl. Bur. Stand. A Phys. Chem. 68(5), 439-448 (1964)

Novatech N.V.: Tec7 Technical Data sheet. In: Novatech N.V. (ed.). Olen (2016)

O' Regan, C.: Structural Use of Glass in Buildings, 2nd ed. The Institution of Structural Engineers, London (2014)

Oikonomopoulou, F., Bristogianni, T., Nijsse, R., Veer, F.A.: Innovative structural applications of adhesively bonded solid glass blocks. In: Vitkala, J. (ed.) Glass Performance Days, pp. 256-261. Tampere (2015a)

Oikonomopoulou, F., Veer, F.A., Nijsse, R., Baardolf, K.: A completely transparent, adhesively bonded soda-lime glass block masonry system. J. Facade Design Eng. 2(3-4), 201222 (2015b). doi:10.3233/fde-150021

Paech, C., Goppert, K.: Innovative Glass Joints-The 11 March Memorial in Madrid. In: Louter, C., Bos, F., Veer, F. (eds.) Challenging Glass: Conference on Architectural and Structural Applications of Glass, pp. 111-118. IOS Press, Delft (2008)

Puller, K., Sobek, W.: Glass-Steel Connections Using Acrylate Adhesives. In: Bos, F., Louter, C., Veer, F. (eds.) Challenging Glass, Delft 2008, pp. 273-278. IOS Press, Amsterdam (2008)

Riewoldt: Riewoldt-Adhesion-Cutting-Die Cutting/ knowledge Center. http://www.riewoldt.de/en/knowledgecenter/fundamentals-of-adhesive-technology/ (2014) 
Schober, H., Schneider, J., Justiz, S., Gugeler, J., Paech, C., Balz, M.: Innovations with glass, steel and cables. In: Glass Performance Days, pp. 198-201. Tampere (2007)

Schott AG: Technical Information: Stress in optical glass. In: Schott (ed.) Advanced Optics. Schott AG, Mainz (2004)

Shand, E.B.: Engineering Glass, Modern Materials, vol. 6. Academic Press, New York (1968)

Shand, E.B., Armistead, W.H.: Glass Engineering Handbook. McGraw-Hill, New York (1958)

Shelby, J.E.: Introduction to Glass Science and Technology: Edition 2 (2005)
Shribak, M.: Polychromatic polarization microscope: bringing colors to a colorless world. Sci. Rep. 5, 17340 (2015). doi:10.1038/srep17340

Tijssen, M.: Transmissie glazen baksteen. In: DIMES. TU Delft, Delft (2014)

Watson, D.M.: Practical Annealing In: 11th Biennial Ausglass Conference, Wagga Wagga 1999. Mc Kinnon (1999)

Wurm, J.: Glass Structures: Design and Construction of Selfsupporting Skins. Birkhauser, Germany (2007) 